Portland State University

PDXScholar

1979

\title{
Variability in test-retest of maximum duration of sustained /a/ in children
}

Elena Diane Norwood
Portland State University

Follow this and additional works at: https://pdxscholar.library.pdx.edu/open_access_etds

Part of the Speech Pathology and Audiology Commons Let us know how access to this document benefits you.

\section{Recommended Citation}

Norwood, Elena Diane, "Variability in test-retest of maximum duration of sustained /a/ in children" (1979). Dissertations and Theses. Paper 2904.

https://doi.org/10.15760/etd.2900

This Thesis is brought to you for free and open access. It has been accepted for inclusion in Dissertations and Theses by an authorized administrator of PDXScholar. Please contact us if we can make this document more accessible: pdxscholar@pdx.edu. 
AN ABSTRACT OF THE THESIS OF Elena Norwood for the Master of Science In Speech Communication presented November 3, 1978.

Title: Variability in Test-Retest of Maximum Duration of Sustained /a/ In Children.

APPROVED BY MERBERS OF THE THESIS COMMITTEE:

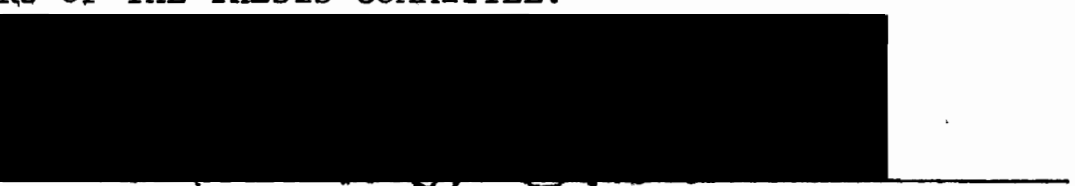

Robert I, Castedi, Chairman
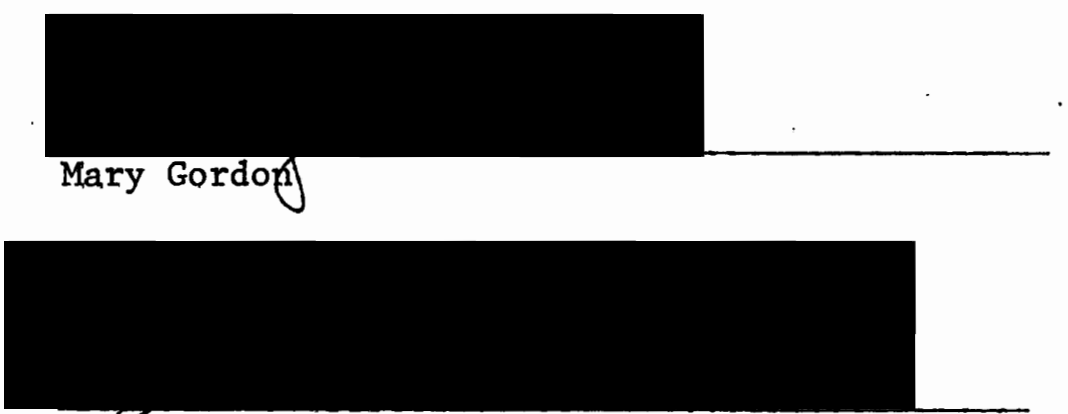

Joan McMahon

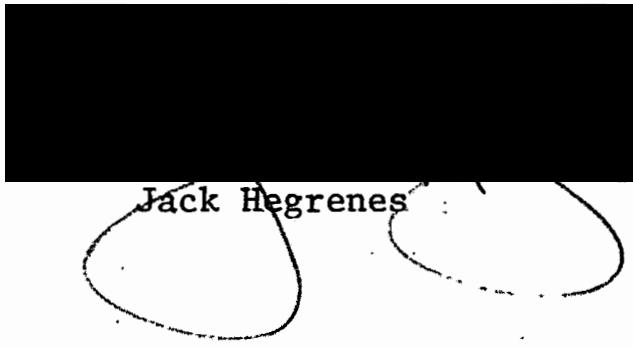

Maximum phonation time has been widely utilized as a simple clinical evaluation of the vocal function. Its importance has been emphasized by Van Riper (1954), Westlake and Rutherford (1961), Boone (1971), and other authors. A review of the literature revealed three trials of sustained phonation have been utilized by most researchers to determine maximum 
duration of phonation. Additionally, the review revealed a lack of test-retest reliability in maximum phonation time in children.

The present study was designed to determine the variability in test-retest of maximum duration of sustained $/ a /$ among prepubescent male and female children. Eighty subjects, twenty at each of the four age levels, seven, eight, nine and ten, were selected from a larger pool using a random order table. Each age level was further divided into two groups of ten male and ten female subjects. A tape recording of twenty maximum phonations of $\mid a /$ was obtained for each subject. A second measure of maximum phonation time was recorded between two weeks and a month following the original run. The essential questions of this investigation were:

1. Given the means of age and sex groups of the longest performance of maximum duration of sustained $/ \alpha /$, is there a significant difference between runs one and two?

2. In the test cohort does the rank order of maximum phonation time differ between runs one and two?

The following secondary questions were also posed:

1. Is there a significantly greater duration of the longest sustained $\mid a /$ when given twenty trials as opposed to the first three trials?

2. Is there a relationship between sex and the duration of sustained $/ \alpha /$ ?

3. Given four prepubescent age groups, is age a factor in relation to length of phonation? 


\title{
VARIABILITY IN TEST-RETEST OF MAXIMUM DURATION \\ OF SUSTAINED / $/$ / IN CHILDREN
}

\author{
by
}

ELENA DIANE NORWOOD

A thesis submitted in partial fulfillment of the requirements for the degree of

\section{MASTER OF SCIENCE IN SPEECH COMMUNICATION with an emphasis in SPEECH PATHOLOGY/AUDIOLOGY}

Portland State University 
TO THE OFFICE OF GRADUATE STUDIES AND RESEARCH:

The members of the Committee approve the thesis of Elena Norwood presented November 3, 1978.

Robert L. Casted1, Chairman
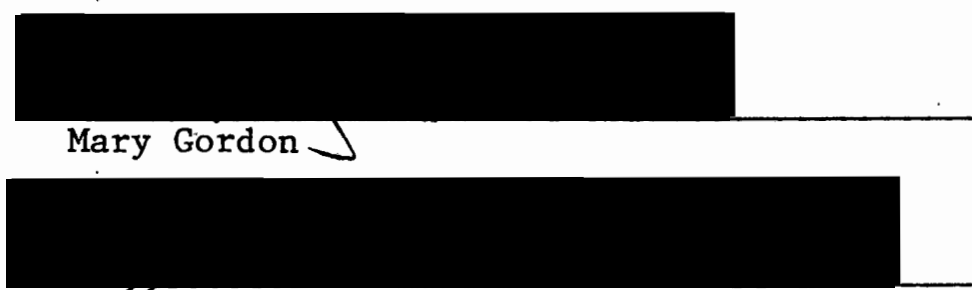

Jodn McMahon

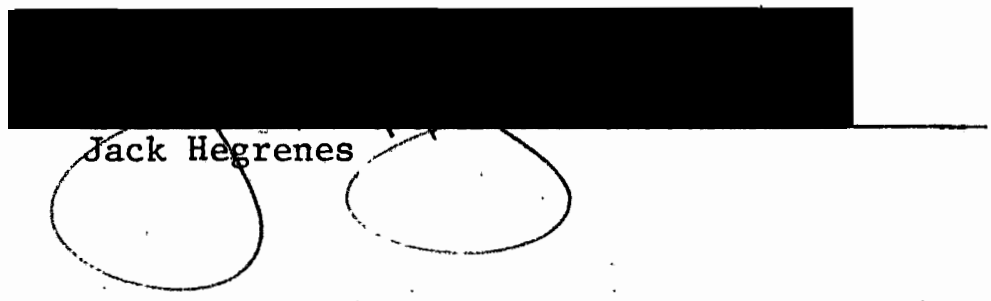

APPROVED :

Robert 1 . Vogflsang, Chárman, Department of Speech Communication

Stanley E. Rauch, Dean of Graduate Studies and Research 


\section{ACKNOWLEDGMENTS}

I am pleased to acknowledge my thanks to all the individuals who helped make this thesis a reality. I wish to express my appreciation to Dr. Robert L. Castee1, Committee Chairman, for introducing me to this area of research and for his support and guidance in the completion of this study. My sincere appreciation to Mary Gordon whose critique of the organization and writing style of this study was invaluable. My thanks to Joan McMahon for her guidance in the design of this study and for her helpful questions along the way. I wish to thank Dr. Jack Hegrenes for his assistance with the statistical analysis of this study and for his valuable input on its content.

I want to thank my friends Teresa Carnese, Patricia Dillon, and Ann Lehman for their patience and love during my graduate studies. My sincere thanks to a special friend, Kathy McCausland, for her continued support, encouragement and assistance in handling the "interstate" footwork involved in getting this study completed. Indeed, I must not forget to thank Portland's Trimet transit system for transporting me safely throughout the city while I conducted my research.

My sincere appreciation to the staff and students at Mt. Tabor, Glencoe and Beaumont Schools for their cooperation and assistance in making this study possible. My special thanks to Virginia Kayser for paving the way for a smooth running project.

Warm thanks to my brother, Stephen, for his continued love and support throughout graduate school, Last, and most especially I want to thank my 
parents, Beth and Bill Norwood, for their love, support and patience throughout my years at Arizona State and Portland State. 
TABLE OF CONTENTS

PAGE

ACKNOWLEDGMENTS . . . . . . . . . . . . . . . . . . . ili

LIST OF TABLES . . . . . . . . . . . . . . . . . . . . vii

LIST OF FIGURES . . . . . . . . . . . . . . . . . . viii

CHAPTER

I INTRODUCTION AND STATEMENT OF PURPOSE . . . . . . . 1

Introduction ................. 1

Statement of Purpose . . . . . . . . . 2

Definitions ................ 3

II REVIEW OF THE LITERATURE . . . . . . . . . . . 4

Prolonged $/ a /$ as a Clinical

Instrument .. . . . . . . . . 4 .

Norms for Maximum Duration of

Phonation . . . . . . . . . . . 5

Previous Research on the Variables

of Maximum Phonation Time . . . . . .

Vital Capacity and Maximum Phonation Time

Vital Capacity and Phonation Time

Air Flow Rate and Maximum

Phonation Time

Vocal Pitch and Intensity

Sex Related to Maximum Phonation Time

Maximum Phonation Time in Children . . . .

Number of Trials Related to

Maximum Phonation Time . . . . . . 13

Summary . . . . . . . . . . . . . 15 
III METHODS AND PROCEDURES . . . . . . . . . . . .

Methods . . . . . . . . . . . . .

Subjects

Instrumentation . . . . . . . . . . .

Procedures . . . . . . . . . . . . . .

Data Collection

Data Measurement

Data Analysis

IV

Results. . ................ 22

Discussion ................. 26

V SUMMARY AND IMPLICATIONS . . . . . . . . . . . . . 44

Summary . . . . . . . . . . . . . . 44

Implications . . . . . . . . . . . . 46

Clinical

Research

REFERENCES CITED

APPENDICES

A PERMISSION REQUEST . . . . . . . . . . . . . 51

B JEWISH HOSPITAL VOICE PROFILE . . . . . . . . . 52

C INSTRUCTIONS FOR ELICITING $/ a /$. . . . . . . . 53 


\section{LIST OF TABLES}

I The Relationship of Maximum Phonation Time

Between Runs One and Two . . . . . . . . .

II Rank-Order Correlation of an Individual

Subject's Maximum Phonation Time Between

Runs One and Two . . . . . . . . . . .

III The Relationship Between Sustained $/ a /$ in

20 Trials as Opposed to 3 Trials Among

7, 8, 9 and 10 Year Old Male and Female

Subjects . . . . . . . . . . . . . . .

IV The Relationship of Sex and Duration of

Sustained $/ a /$ in Prepubescent Children . . . . 


\section{LIST OF FIGURES}

FIGURE

PAGE

1. Percentage of $\mathrm{N}$ Reaching Maximum Phonation Times

for Each of Twenty Trials in Run I . . . . . . .

2. Percentage of $\mathrm{N}$ Reaching Maximum Phonation Times

for Each of Twenty Trials in Run II . . . . . . :

3. Range, Means $(\bar{x})$ and Medians (M) of Maximum

Phonation Times Produced in Twenty Trials in

7, 8, 9 and 10 Year 01d Males for Run I (o) and

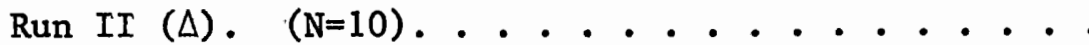

4. Range, Means $(\bar{x})$ and Medians (M) of Maximum

Phonation Times Produced in Twenty Trials in

7, 8, 9 and 10 Year 01d Females for Run I (o)

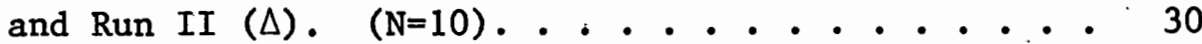

5. Range and Means of the Longest Performance of

Maximum Phonation Times Produced Within the

First Three Trials, First Fifteen Trials and in

Twenty Trials for Seven Year 01d Females Where

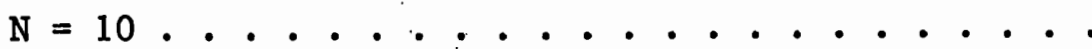

6. Range and Means of the Longest Performance of

Maximum Phonation Times Produced Within the First

Three Trials, First Fifteen Trials and in Twenty

Trials for Seven Year. 01d Males Where $N=10 \ldots . .434$ 
7. Range and Means of the Longest Performance of Maximum Phonation Times Produced Within the First Three Trials, First Fifteen Trials and in Twenty Trials for Eight Year Old Females Where $\mathrm{N}=10$. .

8. Range and Means of the Longest Performance of Maximum Phonation Times Produced Within the First Three Trials, First Fifteen Trials and in Twenty Trials for Eight Year Old Males Where $\mathrm{N}=10 .$. .

9. Range and Means of the Longest Performance of

Maximum Phonation Times Produced Within the First Three Trials, First Fifteen Trials and in Twenty Trials for Nine Year 01d Females Where $\mathrm{N}=10 \quad$. .

10. Range and Means of the Longest Performance of

Maximum Phonation Times Produced Within the First Three Trials, First Fifteen Trials and in Twenty Trials for Nine Year 01d Males Where $\mathrm{N}=10$. . . . 38

11. Range and Means of the Longest Performance of

Maximum Phonation Times Produced Within the First

Three Trials, First Fifteen Trials and in Twenty Trials for Ten Year 01d Females Where $\mathrm{N}=10 \ldots .$.

12. Range and Means of the Longest Performance of

Maximum Phonation Times Produced Within the First

Three Trials, First Fifteen Trials and in Twenty

Trials for Ten Year 01d Males Where $\mathrm{N}=10 . .$. . 
CHAPTER I

INTRODUCTION AND STATEMENT OF PURPOSE

\section{Introduction}

Maximum phonation time has been utilized widely as a clinical evaluation of the vocal function. Its importance has been emphasized by Gutzman (1928), Hayashi (1940), Van Riper (1954), Westlake and Rutherford (1961), Boone (1971), and other authors.

Investigations of maximum duration of phonation with adult populations have been conducted by several researchers (Hayashi, 1940; Arnold, 1955; Ptacek and Sander, 1963;. Yanagihara, Koike and von Leden, 1966; Issh1ki, Okamura and Morimoto, 1967; Yanagihara and Koike, 1967; and Yanagihara and von Leden, 1967). Few studies have used children as subjects; exceptions to this can be found in the studies of Launer (1971), Coombs (1976), and Lewis (1977). The results of these investigations have revealed a wide variance among the subjects' ability to prolong phonation of $/ a /$. The investigations cited have based clinical implications on one to three measurements of maximum phonation time and have not considered test-retest data. Further research is necessary to determine if a subject's ability to prolong phonation of $|a|$ is consistent on retest.

A review of the literature revealed three trials of sustained phonation have been utilized by most researchers to determine maximum duration of phonation. Only recently have more than three trials been utilized as demonstrated in the Lewis (1977) study. Using 20 trials, she investigated 
the maximum duration of phonation of sustained /a/ in children eight and ten years of age when controlling for pitch and intensity. The results of the study revealed only 2 percent of the total sample produced a maximum duration of phonation within the first three trials. It was not until the fourteenth trial that 50 percent of the sample had reached maximum phonation times. These results strongly suggest that maximum duration of sustained $/ a /$ might not be attained within the first three trials by a sample of children. An apparent need exists to determine if twenty trials on other subjects at various ages will demonstrate similar. findings as Lewis' (1977) study as well as determine test-retest performance of the maximum duration of sustained $/ a /$.

\section{Statement of Purpose}

The present study was designed to determine the variability in testretest of maximum duration of sustained $/ a /$ among prepubescent male and female children. The essential questions were:

1. Given the means of age and sex groups of the longest performance of maximum duration of sustained $/ \alpha /$, is there a significant difference between runs one and two.

2. In the test cohort does the rank order of maximum phonation time differ between runs one and two?

The following secondary questions were also posed:

1. Is there a significantly greater duration of the longest sustained $|a|$ when given 20 trials as opposed to the first three trials?

2. Is there a relationship between sex and the duration of sustained $\mid a / ?$ 
3. Given four prepubescent age groups, is age a factor in relation to length of phonation?

\section{Definitions}

$\underline{\text { Tria1 }}$

- Each subject will be given 20 efforts to achieve maximum duration of sustained $/ a /$. Each effort will be referred to as a trial.

Run

Each set of 20 trials will be repeated a second time and each set will be designated as a run. 
CHAPTER II

REVIEW OF THE LITERATURE

\section{Prolonged $|a|$ as a Clinical Instrument}

Maximum phonation time has been widely utilized as a simple clinical test of the vocal function, particularly in the case of vocal fold paralysis (Isshiki et al., 1967). Clinical observations of phonation time yield results which can be utilized to determine phonation variances among individuals with vocal pathologies as well as determine normal function. For example; it was reported by Yanagihara and Koike (1967) and Yanagihara et. a1. (1966) that a substantial decrease in phonation time is often found to accompany severe organic or functional dysphonias. In contrast, a trained healthy voice can sustain phonation a remarkably long time. Döhne (1943), as reported in Isshiki et al. (1967), indicated maximum phonation time was reduced in all cases he tested of unilateral recurrent nerve paralysis with dysphonia; further, an increase of phonation time accompanied improvement of voice.

Others have recommended the clinical use of measuring maximum phonation time. Yanagihara et al. (1966) reported that Hayashi in 1940 measured the maximum phonation time of 20 normal male adults. The vowels used were $/ \mathrm{a} /$ and $/ \mathrm{I} /$; the average phonation times were 22 seconds and 25 seconds, respectively. When compared with normal subjects, patients with vocal nodules or laryngeal polyps produced markedly shorter duration of phonation. This evidence implies maximum duration of phonation signifies efficiency of 
vocal function in each Individual (Yanagihara et al., 1966). 'Fairbanks (1960) stated, "The phonation time is a good indication of efficiency of phonation because vital capacity is reasonably constant." Arnold (1955) contended, "A good criterion for the general quality of the voice is immediately available by determining the phonation time."

\section{Norms for Maximum Duration of Phonation}

Researchers have not agreed on norms for the length of maximum phonation time. Arnold (1955) stated, "In general, phonation time varies between 20 and 30 seconds within the median speaking range." Van Riper (1954) suggested normal individuals should be able to sustain any vowel at least 15 seconds without difficulty. Ptacek and Sander (1963), however, reported in their study that a considerable number of female subjects did not sustain phonation beyond 15 seconds. Fairbanks (1960) reported when pitch and intensity are held constant, the "par" for maximum vowel duration is 20 to 25 seconds. Yanagihara et al. (1966), in a study of 22 adults with equal numbers of each sex, found the average maximum phonation time in men to be 30.2 seconds and 22.5 seconds in females. Beckett (1971) reported, with normal adult subjects, a reasonable mean figure of phonation time would fall between 20 and 29 seconds. Sawashima reported in Isshiki et al. (1967) the mean values of maximum phonation time for males and females with normal voice were 30 seconds and 20 seconds, respectively, and the values below 15 seconds for males and below 10 seconds for females could be regarded as pathological.

Westlake and Rutherford (1961) have analyzed the speaking skill of mạny cerebral palsied children and believe one way to increase speaking 
efficiency is to increase the ability to sustain phonation. Whereas a normal child can easily sustain phonation for 20 seconds or longer with a few initial trial attempts, Ptacek and Sander (1963) reported that Westlake suggested in 1952 that a cerebral palsied child should be able to majntain a sound for a minimum of 10 seconds.

Boone (1971) stated the prepubescent child can sustain an unvoiced sound, e.g., /s/, for about 10 seconds; the average adult can do so for 20 seconds. The individual without vocal fold pathology will extend the unvoiced /s/. and the voiced $/ \mathrm{z} /$ for about the same length of time. When vocal pathology is present, /s/ is sustained twice as long as /z/ due to difficulty in producing phonation.

\section{Previous Research on the Variables of.}

\section{Maximum Phonation Time}

Michel and Wendahl (1971) described voice as a "multi-dimensional series of measurable events, implying that a single phonation can be assessed in many different ways." They defined maximum duration of phonation as the maximum amount of time an individual can sustajn phonation after taking a maximum inhalation. According to Lass and Michel (1969), as reported in Michel and Wendah1 (1971), the variables that affect duration are:

1) the frequency of phonation

2) the sound pressure level of the phonation

3) the vowel being phonated

4) the general physical condition of the individual

5) the amount and kind of training the individual has had, for example, athletes generally do better than non-athletes and trained singers do better than non-singers. 
Vital Capacity and Maximum Phonation Time

According to Michel and Wendahl (1971), vital capacity is the maximum volume of air which can be exhaled following maximum inhalation. They maintained this measure is important only insofar as it provides an estimate of the amount of air potentially available for the production of phonation. Some research has been conducted to determine the relationship between maximum phonation time and vital capacity (Yanagihara, et al. 1966; Isshiki et al., 1967; Yanagihara and Koike, 1967). Yanagihara et al. (1966) reported that Gutzman (1928) noted air volume used during phonation was distinctly smaller than the vital capacity.

Isshiki et al. (1967) discussed the evaluation of maximum phonation time as a vocal function test through an analysis of various factors related to maximum phonation time. The subjects in the study consisted of five males and five females, ranging in age from 20 to 37 years with all having normal voice. The subjects were instructed to take a deep breath, then sustain the vowel as long as possible. This was done at a comfortable pitch and intensity while they were expiring into a spirometer or pneumotachograph through a mask tightly worn on the face. They concluded the whole quantity of vital capacity is never utilized for longest phonation. The percentage of the vital capacity expired during the longest phonation ranged from 68.7 to 94.5 percent. Yanagihara and Koike (1967) also sought to clarify. the relation between vital capacity and the total amount of air volume used for maximum duration of phonation. They obtained similar findings, with the percentages of vital capacity expired ranging from 50 to 80 percent for males, and from 45 to 75 percent for females. 


\section{Vital Capacity and Phonation Volume}

Yanagihara and Koike (1967) presented an investigation designed to clarify the relation between vital capacity and "phonation volume" (the total amount of air volume used for maximum duration of phonation), and to disclose the essential factors necessary to determine the maximum duration of phonation in normal subjects. Air flow rate, total air volume, time duration, vocal pitch, and intensity during sustained phonations of various pitches, were simultaneously measured. The subjects were 22 adults, 11 males and 11 females, none of whom had histories of unusual laryngeal disease, dysphonia, or cardiopulmonary illness. Previous to the actual experiment, each subject repeated phonation for several seconds at a comfortable vocal pitch and intensity using the vowel $/ a /$. This exercise familiarized the subject with the use of the pneumotach-mask and allowed stable reproduction of phonation during the test. Thereafter, the subject inhaled deeply, held the pneumotach-mask tightly, and continued phonation as long as possible, keeping his vocal pitch and loudness constant. These phonations were described as medium, high and low pitch phonation. Generally speaking, phonation volume varied between 2500 and $4500 \mathrm{cc}$ for males and between 1000 and $3000 \mathrm{cc}$ for female subjects. Compared with this wide range of variability in the phonation volume among subjects, the ratio of phonation volume to vital capacity revealed limited variation. The mean values of this ratio on high, medium and low pitch phonations 234368,64 , and 63 percent in male subjects, and 60, 59, and 53 percent in female subjects, respectively. This result points to a close relationship between vital capacity and phonation volume. 
Air Flow Rate and Maximum Phonation Time

Several researchers have investigated air flow rate as it relates to maximum phonation duration and found that phonation time is inversely related to mean flow rate (Yanagihara et al.., 1966; Isshiki et al., 1967; Yanagihara and Koike, 1967; Yanagihara and von Leden, 1967; Hirano, Koike, and von Leden, 1968; and Beckett, 1971). In each case, air flow rate was measured using a pneumotachograph, respirometer or a spirometer.

Isshiki et a1. (1967) suggested in assessing the laryngeal condition on the basis of mean air flow rate it was necessary. for subjects to control the expiratory air force. In their study, using ten adult subjects, they found control of this expiratory force was impractical, and compromised by instructing the subjects to produce only an "easy" maximum phonation. They concluded the great variability in maximum phonation time was partly due to this uncontrolled expiratory force. Additionally, they concluded the mean flow rate.was a better indicator of the glottal condition than maximum phonation time. When no instruments were available to measure the flow rate, the technique of measuring the longest phonation was of clinical value especially in case of marked incomplete closure of the glottis such as in recurrent nerve paralysis.

Utilizing a pneumotachograph, Yanagihara and Koike (1967) found the variation in maximum phonation time among subjects of the same sex was closely related to the difference in the flow rate. Except for medium and low pitch phonations of female subjects, these inverse correlations were found to be statistically significant: Additionally, Hirano, Koike and von Leden (1968) investigated the maximum phonation time, mean flow rate and "phonation quotient" (a quotient of vital capacity divided by the phonation time) of 50 normal adults and 73 pathologic cases. They 
ccncluded there is a significant negative correlation between the maximum phonation time and the mean air flow rate.

An additional purpose of the Isshiki et al. (1967) experiment was to examine the feasibility of using a spirometer as a clinical tool for measuring the air flow during phonation in comparison with a pneumotachographic technique. Statistical analysis of the results revealed there were no significant differences between the results obtained by spirometer and those by pneumotachograph. Furthermore, they stated the cost and complexity of a pneumotachograph limits clinical application of the technique. Beckett's (1971) comparison of the pneumotachograph and respirometer yielded similar findings. He concluded, whereas the pneumotachograph can be used both for clinical and research purposes, the respirometer is better used for clinical purposes alone, with the understanding that some mechanical error will always be present.

\section{Vocal Pitch and Intensity}

Some research has been conducted to determine the effect of vocal pitch and intensity on maximum duration of phonation (Ptacek and Sander, 1963; Yanagihara et al., 1966; and Yanagihara and Koike, 1967). Ptacek and Sander (1963) designed an investigation that primarily measured the ability of young adults to sustain a vowel phonation. Additionally they sought to establish maximum vowel duration measures of subjects using differing intensities and frequencies of phonation. The subjects consisted of 40 males and 40 females. Twelve maximum duration phonations were required of each subject. The conditions were as follows: a) two phonations uncontrolled for either frequency or intensity, b) three frequencyuncontrolled phonations at soft, moderate, and loud intensity levels, 
c) six frequency-intensity controlled phonations, i.e., soft, moderate, and loud phonations at low and high frequencies, d) finally one phonation uncontrolled for either frequency or intensity to explore practice or fatigue effects. During the frequency and intensity controlled tasks, the subjects were allowed to practice until they felt familiar with the task which in most instances was two or three brief practice phonations. Ptacek and Sander concluded from the results that the measures of maximum vowel duration appeared to be a function of both the frequency and intensity of the subjects' phonations. However, the group mean duration differences between vowels prolonged at soft, moderate, and loud intensities were relatively small when the phonations were at a low frequency or uncontrolled for frequency.

In a somewhat similar format, Yanagihara and Koike (1967), in studying 22 adults, instructed each subject to use high, medium, or low pitches and appropriate loudness of voice where it could be sustained. without specific effort. They concluded greater voice intensity was generally associated with larger mean flow rate at high pitches, while no predictable relation existed between voice intensity and mean flow rate on medium and low pitch phonations. Additionally, they observed a notable decrease in the phonation time with the rise in pitch from medium to high, which can be attributed to the increase in the flow rate during high pitch phonation.

Sex Related to Maximum Phonation Time

Several researchers have investigated the maximum duration of phonation in both male and female adult subjects (Ptacek and Sander, 1963; Yanagihara et al., 1966; Yanagihara and Koike, 1967; and Yanagihara and 
von Leden, 1967). The results of the Ptacek and Sander (1963) study indicated that male subjects, in general, tended to sustain phonation longer than female subjects. Yanagihara and Koike (1967) reported at any pitch there was considerable difference in maximum phonation time between the female and male subjects in their study with the latter being longer in diration. In reviewing the literature of investigations involving adults, these findings are representative of studies regarding sex differences in phonation time.

\section{Maximum Phonation Time in Children}

The review of the literature thus far has been based on studies using adult populations. Few studies have been conducted using children as subjects; exceptions to this can be found in the studies of Launer (1971), Coombs (1976), and Lewis (1977). Launer (1971) measured the phonation time of 206 boys and girls ranging. in age from seven to eighteen years. While controlling for pitch and loudness levels, she investigated the relationship between the three variables of age, sex, and body size and the length of phonation of the sustained vowels $/ a /, / i /$, and $/ \mathrm{u} /$. The research indicated phonation time increases as age increases and that male children phonate longer than female children. In addition there was no significant difference in the phonation of the three vowels. Launer noted the variables of sex, age, height and weight were overlapping predictors. She stated: "...given height and weight, age and sex add no independent information, or, given age and sex, height and weight give no additional information."

Coombs (1976) conducted an investigation comprising a total of 190 subjects ranging in age from six to ten, of which 38 children exhibited 
normal voices and 152 exhibited hoarse voices. Coombs sought to determine the effects of the variables of severity of hoarseness, sex, and/or age on the length of phonation of $|a|$. The results indicated the three variables of degree of hoarseness, sex, and age collectively affect duration of phonation of $/ a /$. Sex was not found to be a statistically significant factor affecting length of phonation. It was further noted that as hoarseness increased, the duration of phonation of $/ a /$ decreased and as age increased, phonation time also increased. An analysis of varlances showed only 27.31 percent of the variance between subjects' phonations of $|a|$ could be explained by the three variables of degree of hoarseness, sex and age.

Lewis. (1977) conducted an investigation to determine the effects of age, sex, height, weight and vital capacity on the maximum duration of phonation of sustained $/ a /$ when controlling for pitch and intensity. This study consisted of 20 female and 20 male children collectively, at two age levels, eight and ten. The results of her study indicated the five varlables, age, sex, vital capacity, helght and weight, collectively affected maximum duration of sustained $/ \alpha /$. There was a significant correlation between vital capacity and phonation time. Sex was a statistically significant factor affecting phonation time, with male subjects tending to phonate longer than female subjects; whereas the variables age, height and weight were not statistically significant factors affecting phonation time.

Number of Trials Related to Maximum Phonation Time

Previous investigations, cited in earlier paragraphs, have based 
their results on three trials or less to obtain maximum phonation of lal (Yanagihara et a1., 1966; Yanagihara and von Leden, 1967; Yanagihara and Koike, 1967; Launer, 1971; and Coombs, 1976). As previous1y reported, Ptacek and Sander (1963) designed an investigation in which a total of 12 maximum duration phonations were required of each subject. It was their purpose to establish maximum vowel duration measures of subjects under differing intensities and frequencies of phonation. No consistent practice or fatigue effects could be inferred from a comparison of the first of the phonatory tasks with the last of the 12 phonations. of the researchers mentioned above, Yanagihara and Koike (1967) were the only ones that included a rationale for three trials of maximum phonation. Each subject was instructed to use the most appropriate loudness of voice for maximum continuation of phonation. The phonations were produced at three different pitch levels: 1) at the easiest and most comfortable pitch; 2) at the highest pitch in chest register sustainable without special effort; and 3) at the lowest pitch sustainable without special effort. These phonations were described as medium, high, and low pitch phonation, respectively. The medium pitch phonation was repeated three times; the first record of each subject was discarded because unfamiliarity with the examination often affected the first sustained phonation. Intrasubject variations of duration of phonation were tested by comparing the second and third trials of the medium pitch phonation. It was confirmed by the results that the differences in these measures between the two consecutive records were small enough to permit using the mean value as a representative measure of the medium pitch phonation. Based on the review of the literature, Lewis (1977) additionally 
sought in her study to determine if, when given 20 trials, the maximum duration of $\mid a /$ would occur beyond the third trial. Given 20 trials, the Lewis findings indicated only one subject out of a sample of 40 reached maximum duration of phonations of $|a|$ by the third trial. Additionally, it was found that within the first three trials, 37 of 40 subjects failed to reach the mean for sustained $/ a /$, obtained in 20 trials for their subgroup. What is even more significant is that 50 percent of the sample did not reach maximum phonation time until the fourteenth trial. The results of the Lewis (1977) study strongly suggest maximum duration of sustained $/ a /$ might not be attained within the first three trials by a sample of children.

\section{Summary}

Some investigations by researchers have revealed a wide variance among the subjects' ability to prolong phonation of /a/ (Ptacek and Sander, 1963; Yanagihara and Koike, 1967; Launer, 1971; Coombs, 1976; and Lewis, 1977). The investigations cited, other than Lewis (1977), have based their clinical implications on one to three measurements of maximum phonation time.

Further research is necessary to determine if a subject's ability to prolong phonation of $/ a /$ is consistent on a retest. The review of literature summarizes research that has been published in the area of maximum phonation time. An outstanding feature in the literature is that no one has looked at test-retest reliability. Ptacek and Sander (1963) in their study cautioned against making statements about individual variability in maximum phonation time until collection of complete test-retest 
data concerning the various controlled measures of phonation is available. An apparent need exists to determine if 20 trials on other subjects at various ages will demonstrate similar findings as Lewis' (1977) study as well as determine test-retest performance of the maximum duration of sustained $/ a /$. 
CHAPTER III

METHODS AND PROCEDURES

Methods

\section{Subjects}

The subjects for this investigation were chosen from a pool of approximately 190 children at age levels seven, eight, nine and ten. There was a variance of plus or minus three months at each of the four age levels. For data analysis 80 of the subjects, 20 at each of the four age levels, were selected using a random order table. Each age level was further divided into two groups of 10 male and 10 female subjects. The children were all students at Beaumont, Mt. Tabor and Glencoe Elementary Schools in Portland Public Schools, Area III, Portland, Oregon.

Letters of permission initially were sent home with all seven, eight, nine and ten year old children attending Beaumont Elementary School (see Appendix A). Additional schools were added when more subjects were needed for the study. Letters of permission at Mt. Tabor and Glencoe Elementary Schools were distributed only to those children who met the age stipulation. Children whose parents did not return the letters were eligible for the screening. The purpose of the screening was to rate the children's voices. Only those who were rated as normal based on the Jewish Hospital Voice Profile were chosen as subjects for the investigation. There were additional subject screening criteria: The children were 
observed by this examiner to be free of colds and were otherwise able to comply with the instructions for eliciting maximum phonation of $|a|$.

\section{Instrumentation}

A Sony reel-to-reel tape recorder, Model 非C-104A, was used in conjunction with TDK S-1800 magnetic tapes to record each subject's maximum phonations of $/ a /$. A Breitling stopwatch was used to measure the duration of phonations. Each subject's voice quality was rated using the Jewish Hospital Voice Profile, presented in Appendix B. The profile has a scale for judging six parameters of voice production: pitch, degree of openness of the vocal folds, nasal resonance, rate, intensity, and vocal range. The profile also provides a severity rating scale for recording from "1" to "7" with " 1 " representing a barely perceptible problem and "7" indicating a problem that interferes significantly with communication. Only subjects judged to be within normal limits for the parameters of pitch, degree of openness of the vocal folds, rate, intensity, and yocal range were included in this investigation.

On the voice profile, the "A" Scale was used to rate the open and closed positions of the vocal folds. According to Wilson (1971), a rating of " -4 " on this scale indicates the folds are totally open and there is little, if any, friction produced during communication; "- 3 " indicates whispered phonation; " 2 " represents breathiness; "1" Indicates a normal voice; " +2 " represents a voice that is characterized by strained production accompanied by much tension; and " +3 " Indicates extreme tension with random closure and the production is characteristic of those individuals with spastic dysphonia. A rating of. " $+2 /-2$ " Indicates a voice which is tense, strained and breathy, which is commonly known as a hoarse voice quality. 
Scale "B" was used to rate "Laryngeal Capacity" of pitch. On this scale a rating of " +3 " and " -3 " respectively indicates that an individual speaks either too high or too low for a listener to determine sexual identification based on voice. A " +2 " or a "-2" rating represents pitch deviations noticeable only to the critical listener. A rating of "1" indicates a normally pitched voice.

Scale "C" represents "Resonating Cavity" or nasality. A rating of "-2" represents hyponasality, "1" represents normal nasal resonance, "+2" indicates assimilation nasality, " +3 " represents nasalization of vowels with a slight nasalization of consonants, and " 4 " indicates nasalization af both vowel and consonant sounds.

\section{Procedures}

\section{Data Collection}

The screening and taping of test runs took place in an empty classroom where it was reasonably quiet. A conversational sample was obtained, in which each child spoke to the examiner in response to questions. This voice sample was then used to screen for normal voice. A normal voice was defined as one rated "1.5" or below on the severity scale for ratings on scales $A$ and $B$ of the profile. The rate and intensity of each subject's voice. was evaluated by the examiner to be within normal limits for children. Nasality was not rated for this investigation.

A tape recording of twenty maximum phonations of $\mid a /$ was obtained for each subject. A microphone was held by the examiner 4 to 6 inches from each subject's mouth. Each subject phonated at a pitch approximately one-fourth from the bottom of his/her frequency range. This was determined 
by the examiner for each individual child in the following manner: each child was instructed to phonate $/ a /$ in his lowest voice; this frequency was identified on a pitch pipe, and a frequency three notes above that lowest frequency was modeled by the examiner at the pitch the subject was to use in phonating $/ \alpha /$. Intensity was modeled and shaped by the examiner to represent an intensity level in the lower half of the conversational range.

The present investigation closely approximated the methods used in the Lewis (1977) study so that the results of the two studies could be compared. Therefore, Lewis' (1977) instructions for eliciting maximum phonations of $/ a /$ were used in the present study (see Appendix $C$ ).

\section{Data Measurement}

The voice samples were analyzed by this examiner who was trained to use the Jewish Hospital Voice Profile by Robert L. Casteel, Ph.D., and Mary E. Gordon, M.S., voice clinic supervisors at Portland State University. The above-mentioned clinical supervisors conducted a training session for calibration of this examiner using the Jewish Hospital Voice Profile training tapes and previous Portland State University research tapings of volce samples. It was the goal of the training session to reach interjudge agreement of 90 percent for two consecutive sets of ten undiscussed samples. Agreement among judges was defined as ratings within a range of one point on the "severity scale" and in complete agreement on scales " $\mathrm{A}$ " and "B". of the Jewish Hospital Voice Profile.

Discussion of the voice samples was allowed after each set of ten samples. The criterion of 90 percent interjudge agreement was met on the eighth and ninth set of samples. There was no discussion among the judges 
during or between the presentations of these two sets.

The twenty phonations of $/ \alpha /$ for each subject were measured from the tape recording. The durations of the phonations were measured to the nearest one-tenth second using a stop watch. The longest phonation time produced during the twenty trials was considered to be that subject's maximum duration of sustained $/ a /$. A second measure of maximum phonation time was recorded between two weeks and a month following the original run. A random order table was employed to choose eighty subjects to be analyzed, from a larger pool of subjects completing runs one and two. This accounted for any absentee difficulties that occurred.

\section{Data Analysis}

A one-tailed $\underline{t}$-test for related measures was used to determine the significance of difference between runs one and two of maximum duration of sustained $|a|$. Additionally, t-tests were used to determine the significance of sex and number of trials to maximum phonation time. The Spearman Rank-Order Correlation (rho) was used to assess the relationship between individual subjects' maximum phonation time relative to others between runs one and two.

Inspection from graphic representations were used to determine the

following: (1) The percentage of total population reaching maximum phonation times on each of the twenty trials; (2) Range of maximum phonation times produced in 20 trials with the mean and median for each group; (3) Range and means of maximum phonation times produced in 3, 15 and 20 trials; (4) The relationship of age to length of phonation. 
CHAPTER IV

RESULTS AND DISCUSSION

\section{Results}

The purpose of this investigation was to determine the variability in test-retest of maximum duration of sustained $/ a /$ among prepubescent male and female children. Two major and three minor questions were posed in this investigation. The first of the primary questions was: Given the means of age and sex groups of the longest performance of maximum duration of sustained $/ \alpha /$, is there a significant difference between runs one and two? The data were analyzed using a one-tailed t-test for related measures. The summary of the statistical analysis appears in Table $I$. Seven of the eight $\underline{t}$-tests revealed the differences between runs one and two were not statistically significant at .05 probability with nine degrees of freedom.

The second primary question posed was: In the test cohort does the rank order of maximum phonation time differ between runs one and two? The Spearman Rank-Order Correlation Coefficient (rho) was utilized to determine the correlation between an individual's performances on runs one and two when categorized by age and sex. Table II indicates there is a high correlation between an individual's performances on runs one and two. The exception to this trend was the results of eight year old males and nine year old females for which there was a slight correlation. 


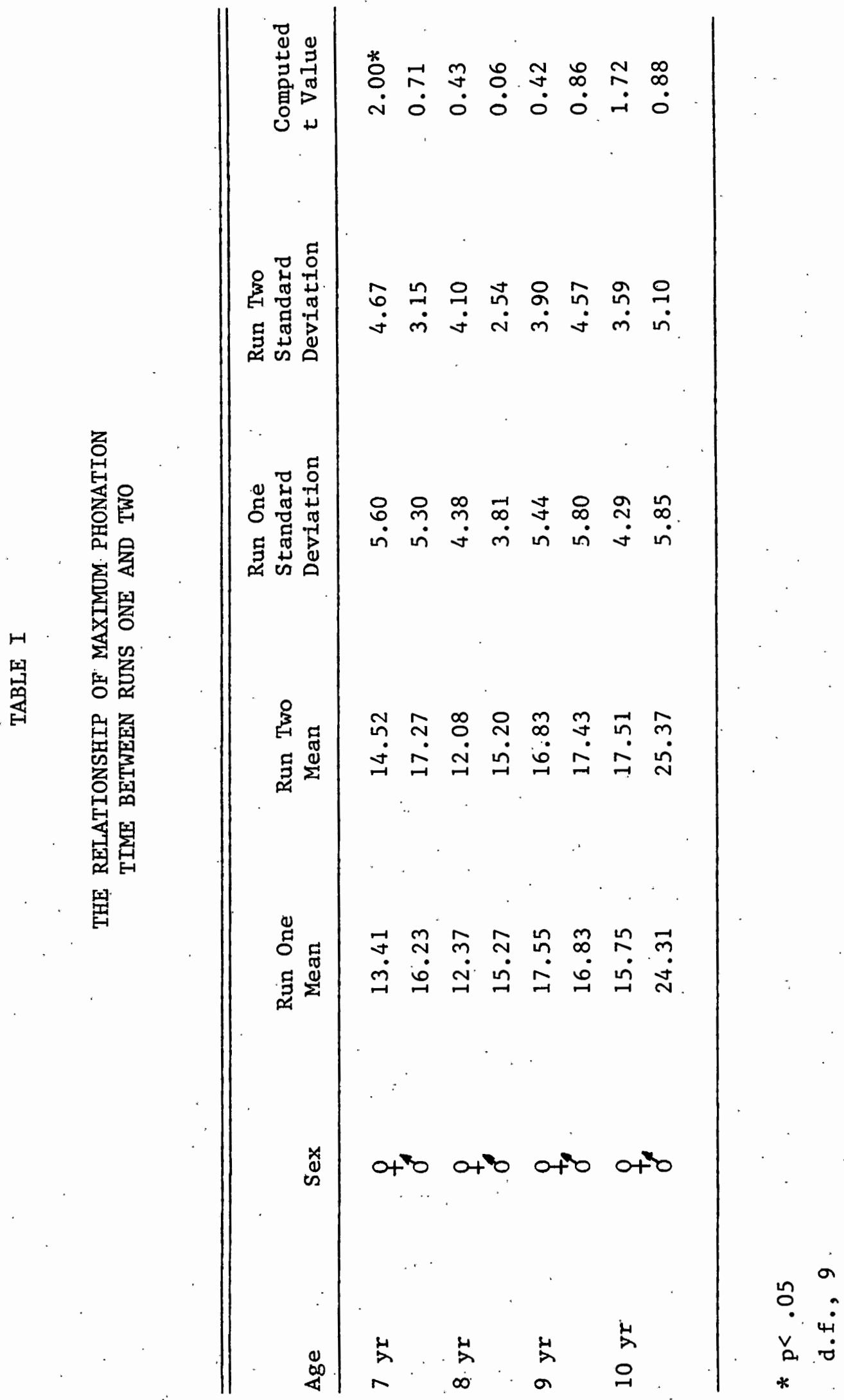


TABLE II

RANK-ORDER CORRELATION OF AN INDIVIDUAL SUBJECT'S

MAXIMUM PHONATION TIME BETWEEN RUNS ONE AND TWO

\begin{tabular}{|c|c|c|c|}
\hline Age & Sex & $\mathrm{r}_{\mathrm{s}}$ (rho) & Correlation* \\
\hline 7 & $q$ & 0.92 & Very High \\
\hline 7 & $\sigma^{\prime}$ & 0.38 & Low \\
\hline 8 & $q$ & 0.89 & High \\
\hline 8 & 8 & 0.09 & Slight \\
\hline 9 & $q$ & 0.15 & Slight \\
\hline 9 & 8 & 0.88 & High \\
\hline 10 & $q$ & 0.67 & Moderate \\
\hline 10 & 8 & 0.75 & High \\
\hline
\end{tabular}

The first of the secondary questions posed was: Is there a significantly greater duration of the longest sustained /a/ when given twenty trials as opposed to the first three trials? The greater duration of the longest sustained $\mid \alpha /$ when given twenty trials as opposed to the first three trials was determined to be statistically significant at the .025 probability level or less using a one-tailed t-test for related measures with nine degrees of freedom. See Table III for the results. Additionally, five groups of the total eight exceeded the .005 level to .0005 probability leve1. 


\section{TABLE III}

THE RELATIONSHIP BETWEEN SUSTAINED / $a$ / IN 20 TRIALS AS OPPOSED TO 3 TRIALS AMONG

7, 8, 9, AND 10 YEAR OLD MALE AND FEMALE SUBJECTS

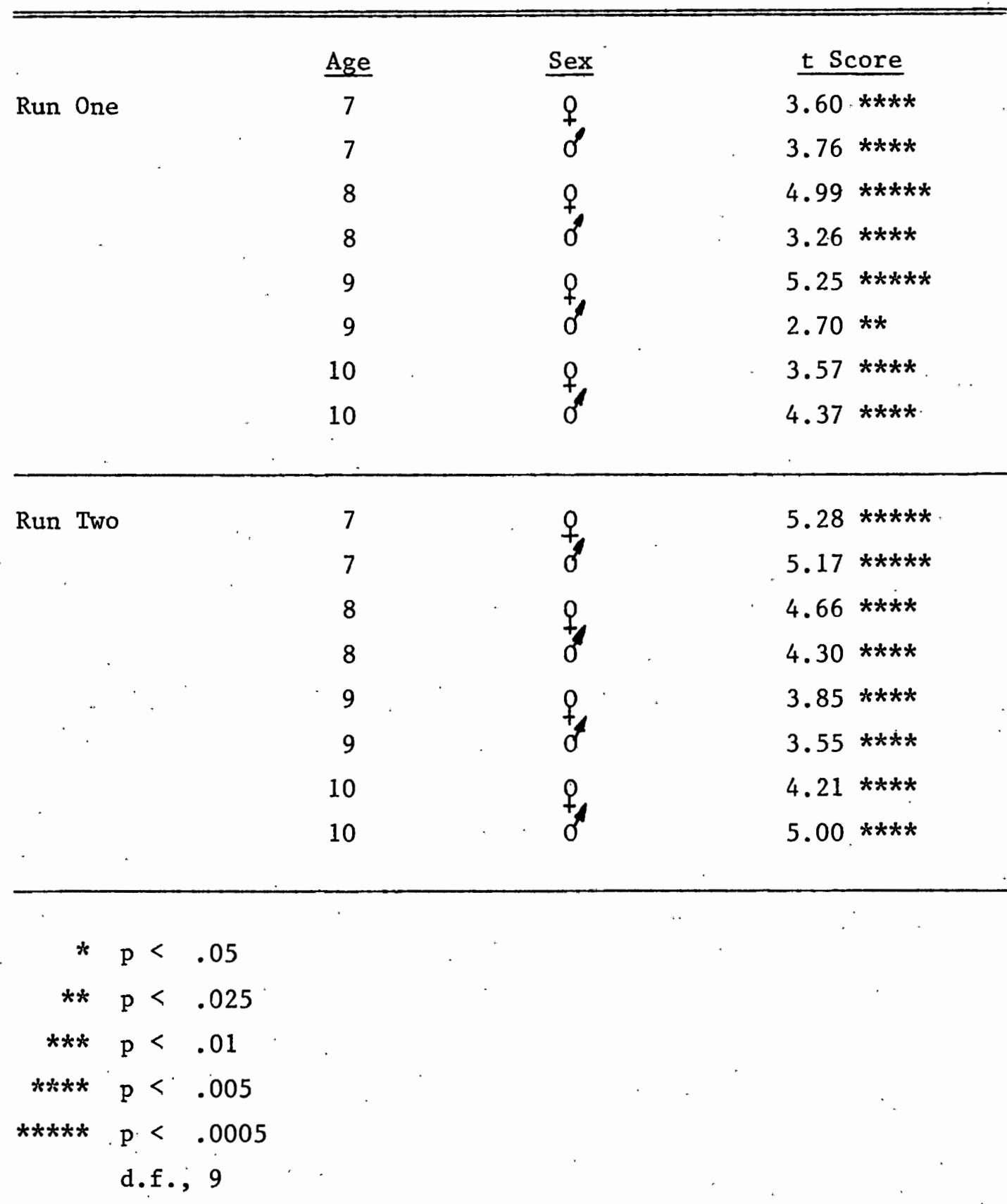


Further data were compiled on the number of trials. The determination of when 50 percent of the total sample reached maximum phonation time for runs one and two was determined by inspection from a cumulative graphic representation. The results indicated that the percentage of the total sample producing a maximum duration of phonation within the first three trials was. 8.75 percent for run one and 6.25 percent for run two. For each of the runs one and two, it was not until the fourteenth trial that 50 percent of the subjects had reached maximum phonation times and not until the twentieth trial that all eighty of the subjects produced maximum phonation (see Figures 1 and 2).

The next secondary question posed was: Is there a relationship between sex and the duration of. sustained /a/? Table IV indicates sex was shown to have no relationship to the length of phonation at the .05 probability level using a one-tailed $t$-test for unrelated measures with eighteen degrees of freedom. Exceptions to this were found in eight year old males and females on run two and ten year old males and females on both runs.

The last question posed was: Given four prepubescent age groups, is age a factor in relation to length of phonation? The answer to this question was determined by inspection from a graphic representation. The results indicated as age increased so did phonation time (see Figures 3 and 4).

\section{Discussion}

The purpose of this investigation was to determine the variability in test-retest of maximum duration of sustained /a/ among prepubescent 


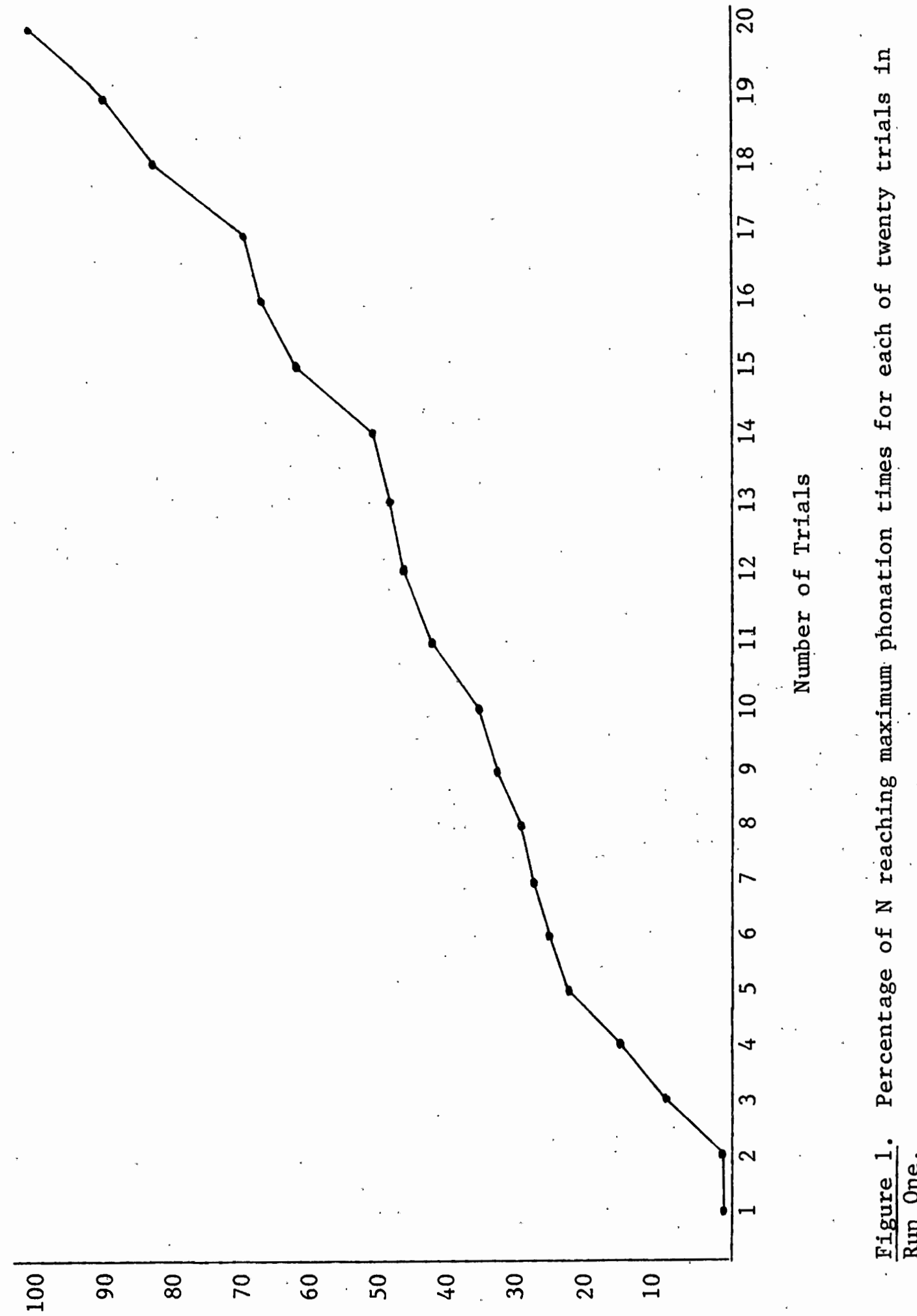

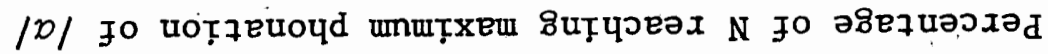




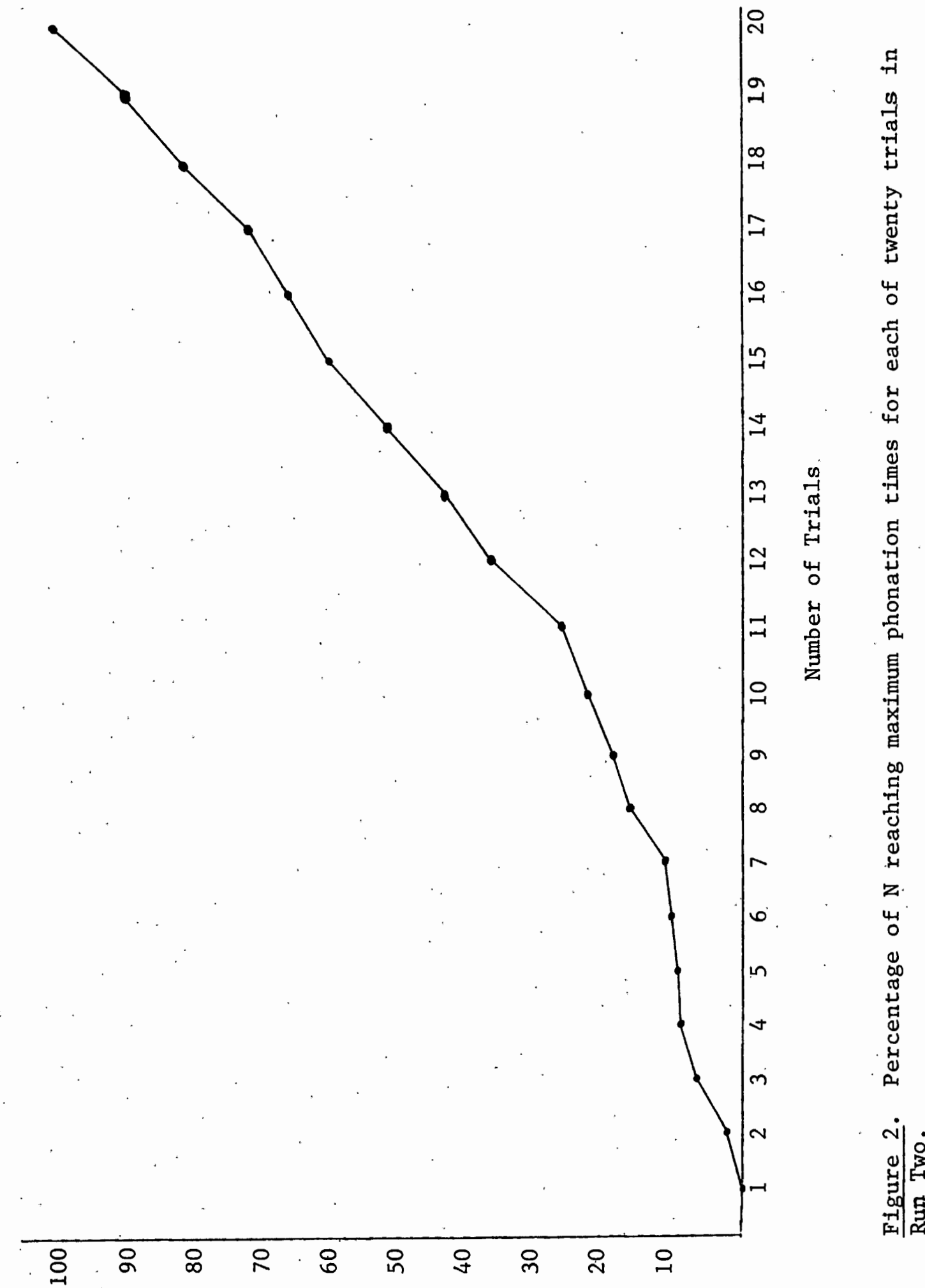

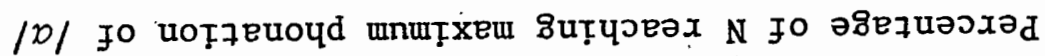


TABLE IV

THE RELATION OF SEX AND DURATION OF

SUSTAINED $/ a /$ IN PREPUBESCENT CHILDREN

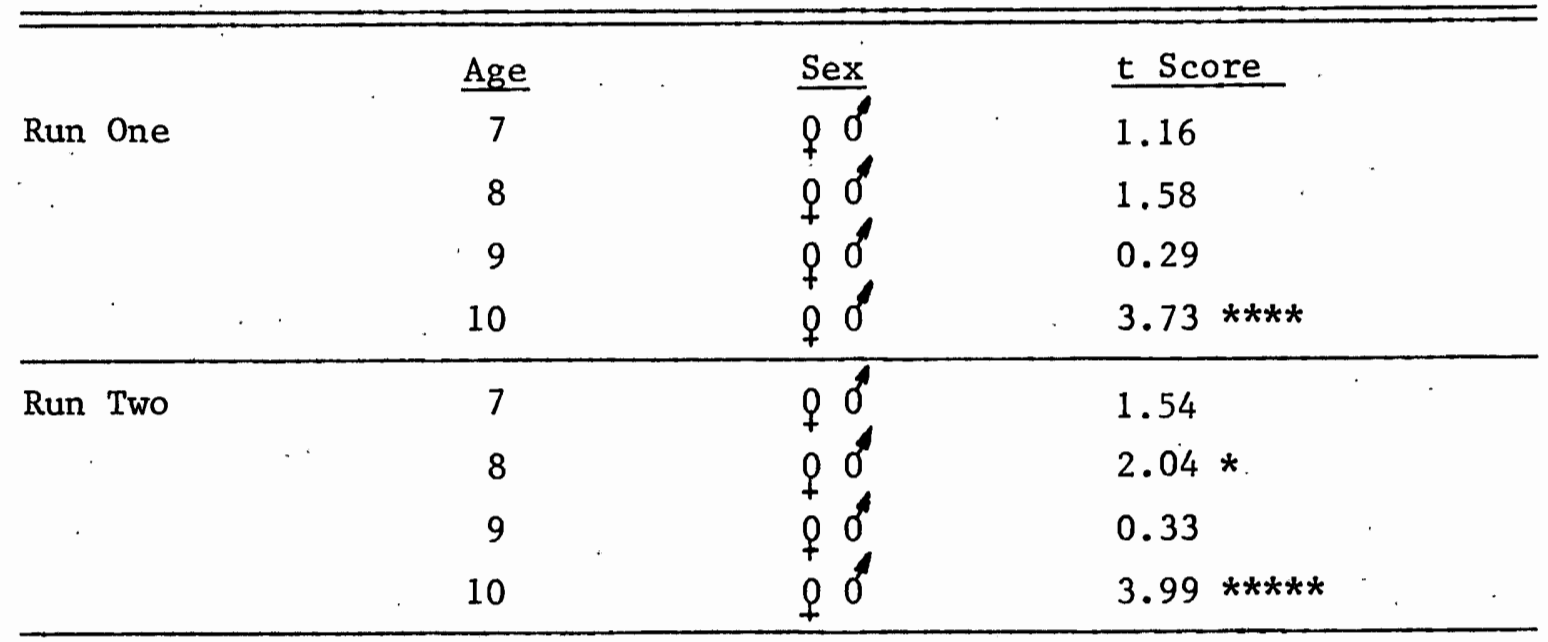

$$
\begin{array}{rl}
* \mathrm{p} & <.05 \\
* * \mathrm{p} & <.025 \\
* * * \mathrm{p} & <.01 \\
* * * * & \mathrm{p}<.005 \\
* * * * * & \mathrm{p}<.0005 \\
\text { d.f. } 18
\end{array}
$$

male and female children. The results of this investigation indicated the differences between runs one and two were not significant. Additionally, a high correlation was found between individuals' performances on runs one and two. Thus, the results of the present study show a consistency in performance between runs one and two. Additionally, it was revealed that three trials were not adequate to illustrate this consistency.

Previous research has not been conducted in test-retest on maximum phonation time. Ptacek and Sander (1963) in their study cautioned against making statements about individual variability in maximum phonation time until collection of complete test-retest data concerning the various controlled measures of phonation is available. The present study found a high 
$\stackrel{n}{v}$
$\stackrel{n}{N}$
$\stackrel{N}{\pi}$
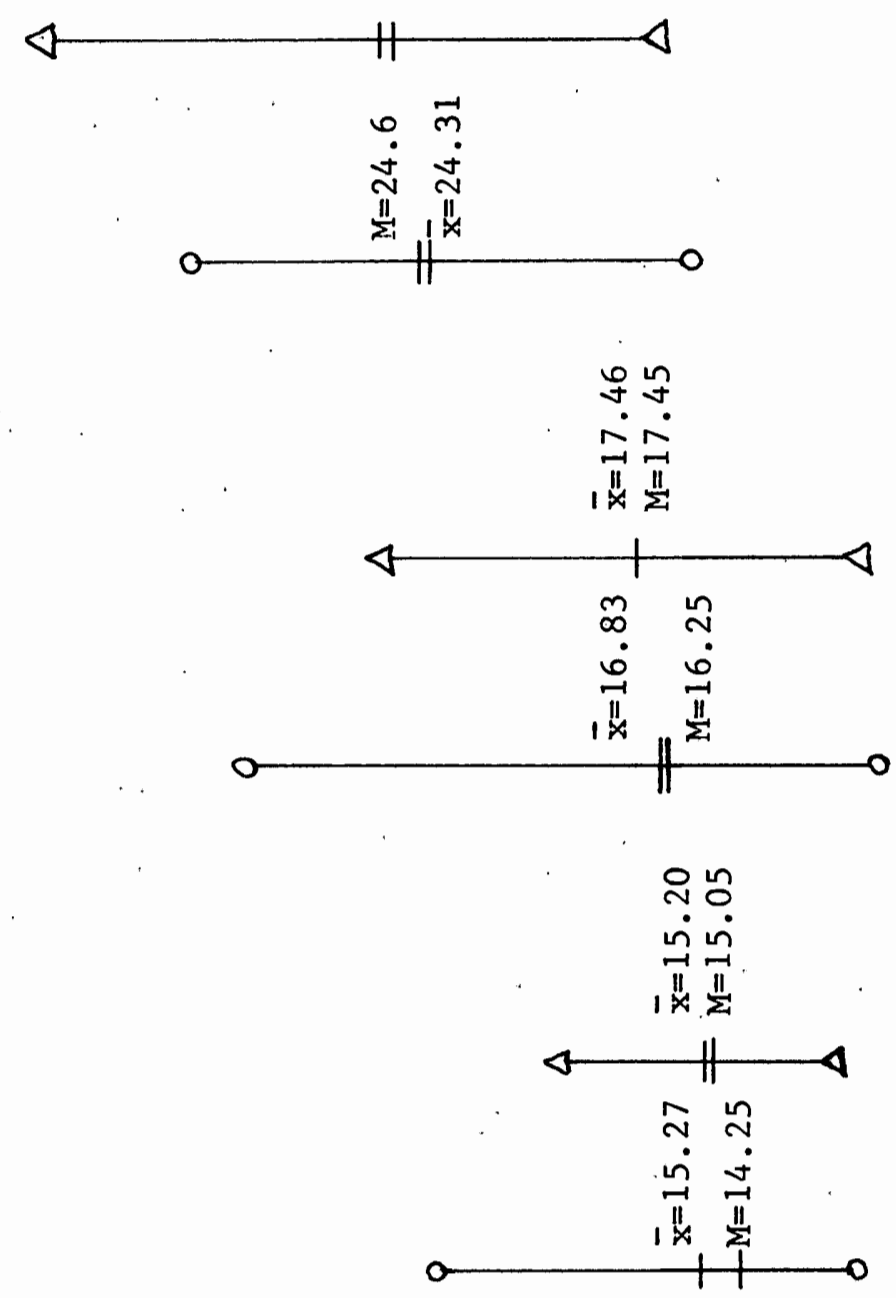

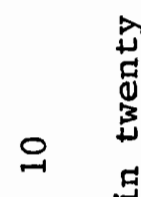

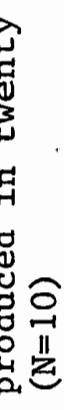

兽

の

䄏

đI

出党

结

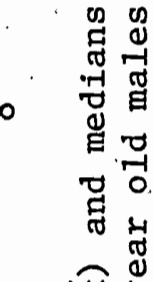

ㅊำ은

in

iI
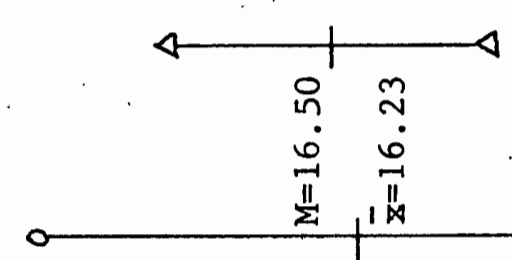

$1 x$

营

$\wedge \quad 0^{0} \infty$

กั

م.

m 


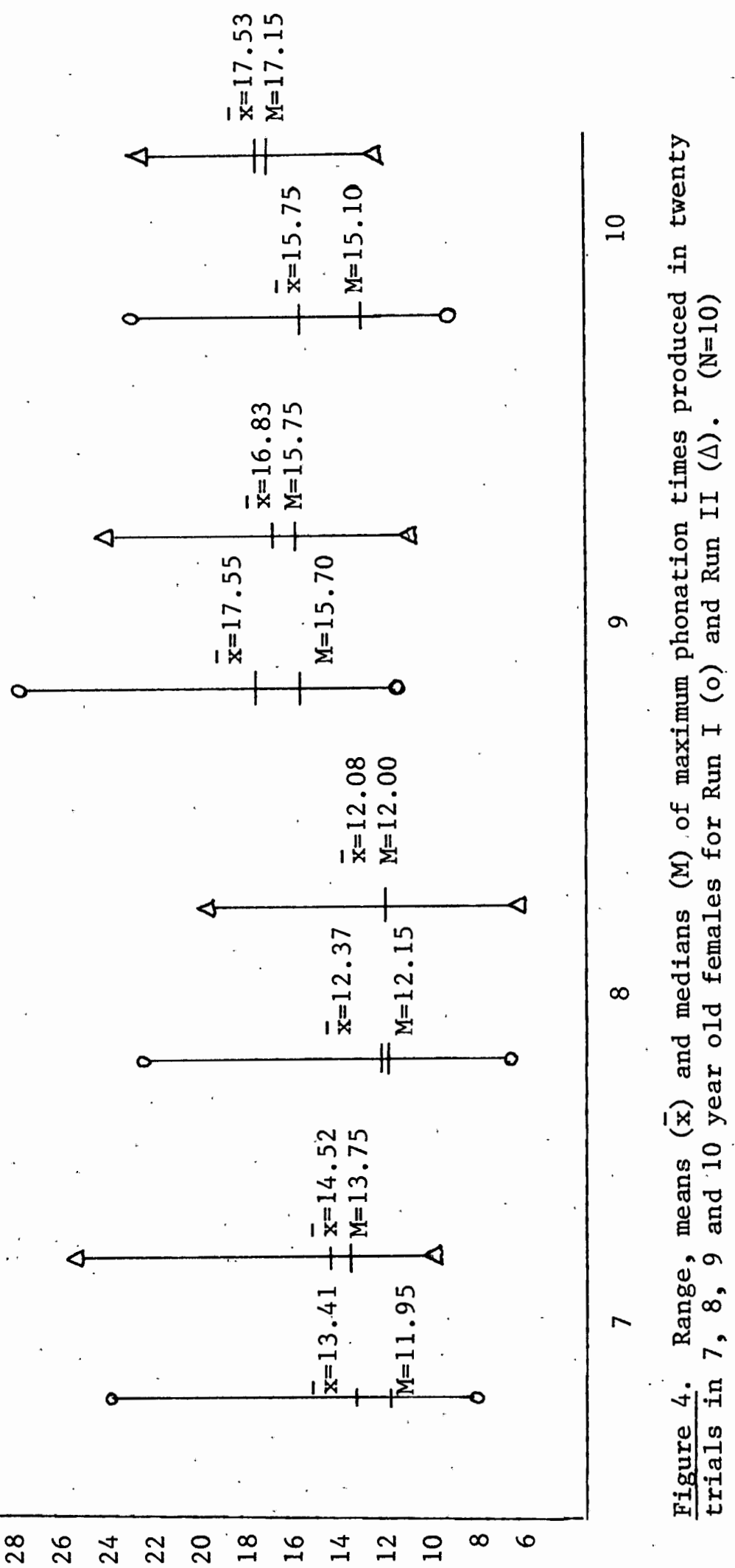

spuopas uT /D/ fo uoffeuoyd unnțxeu fo ә8ินey 
correlation of individual's performance between runs one and two. There is further support for this in that there was no significant difference between the means of runs one and two.

The results of the present study lend support to Lewis (1977) who indicated that twenty trials of maximum duration of sustained /a/ yielded a more accurate representative sample of a child's ability to phonate $/ a /$ than that of three trials. In her investigation, only one subject (2 percent) of a total sample of forth subjects produced maximum duration of phonation within the first three trials. It was not until the fourteenth trial that 50 percent of the population had reached maximum phonation times. Lewis reported that the results of her investigation strongly suggested that maximum duration of sustained $/ a /$ probably would not be attained within the first three trials by a population of children.

In this investigation, of the total sample, only 8.75 percent for run one and 6.25 percent for run two produced a maximum duration of phonation within the first three trials. Additionally, in agreement with the Lewis (1977) findings, it was not until the fourteenth trial of both runs one and two that 50 percent of the subjects had reached maximum phonation times.

In reviewing the literature it appears most researchers used one to three trials. However, those who have suggested maximum phonation times for normal voiced individuals (Van Riper, 1954; Arnold, 1955; Fairbanks, 1960; Wesțlake and Rutherford, 1961; Yanagihara et a1., 1966; and Boone, 1971) have not indicated the number of trials used to obtain these results. The results of this investigation indicate there is minimal change in maximum phonation time beyond the fifteenth trial when 
given a total of twenty trials (see Figures 5-12). By visual inspection it appears that beyond the fifteenth trial the group means, by age and sex, of maximum phonation time approach asymptote; that is, the means tend to increase up to the fifteenth trial and then level off between trials sixteen through twenty.

Researchers have suggested various maximum phonation times for normal voiced individuals. Van Riper (1954) reported a normal voiced individual should be able to sustain a vowel for fifteen seconds. Other researchers, Westlake and Rutherford (1961) maintain a normal child can easily sustain phonation for twenty seconds. An important point is that the above-mentioned researchers make statements about what is normal phonation time without any presented research to support their statements. Seventy-eight percent of the eighty subjects in this investigation on run one failed to reach the suggested maximum phonation time of fifteen seconds in the first three trials, and 46 percent in twenty trials. Run two yielded similar results. Sixty-nine percent of the eighty subjects failed to reach suggested norms in the first three trials, and 41 percent in twenty trials. The results of the present investigation lend support to the findings of the Lewis (1977) study. Fifty percent of the forty subjects in the Lewis study failed to reach the suggested norm of fifteen seconds in the first three trials. Five of the forty subjects ( 12.5 percent) failed to reach this norm within twenty trials. The research currently being conducted in the area of maximum phonation time disagrees with previous norms of maximum phonation time. The results of the present investigation and the Lewis (1977) study suggest that further collection of normative data are necessary to establish norms for maximum phonation time. 


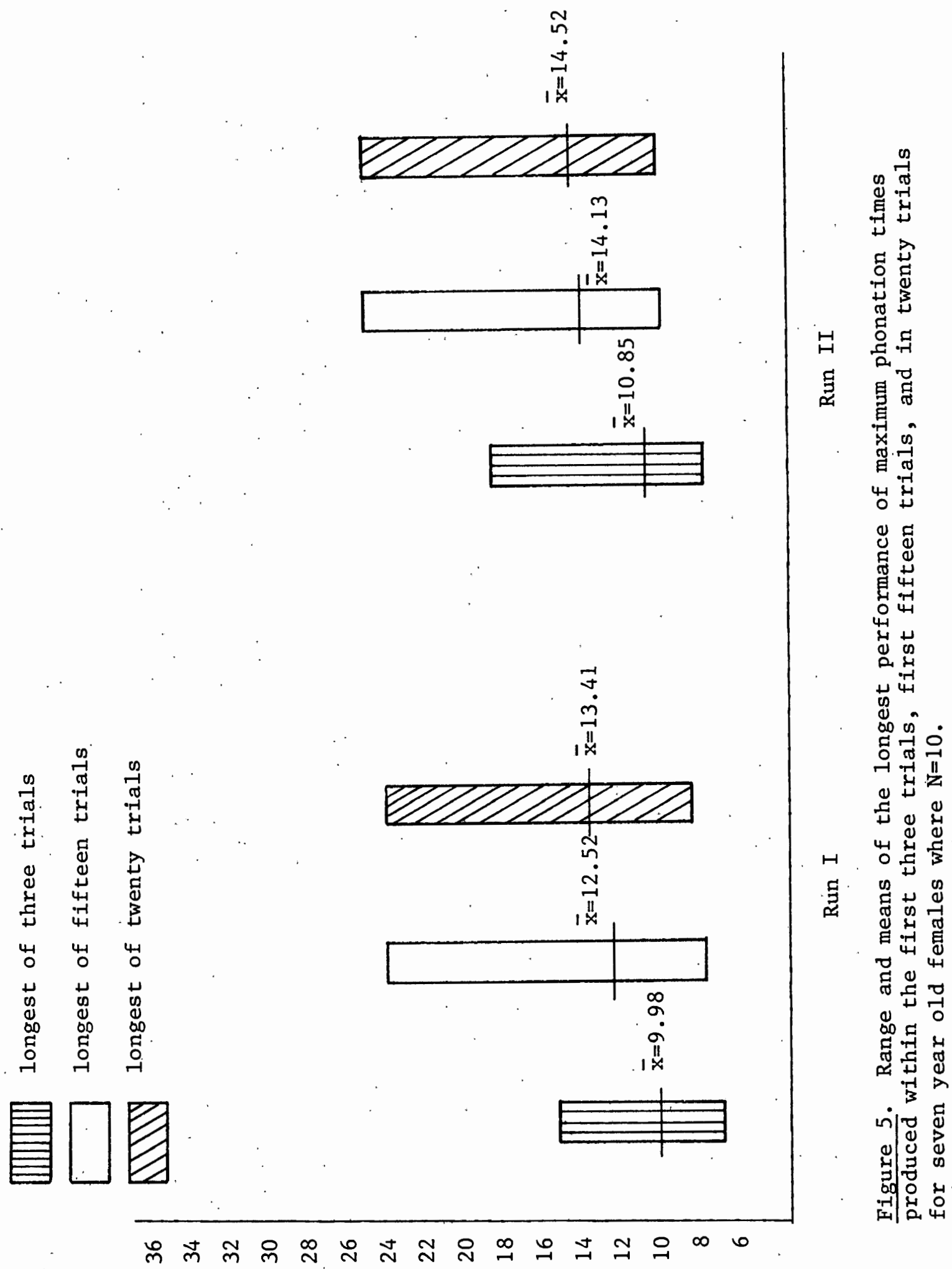

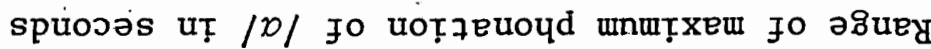



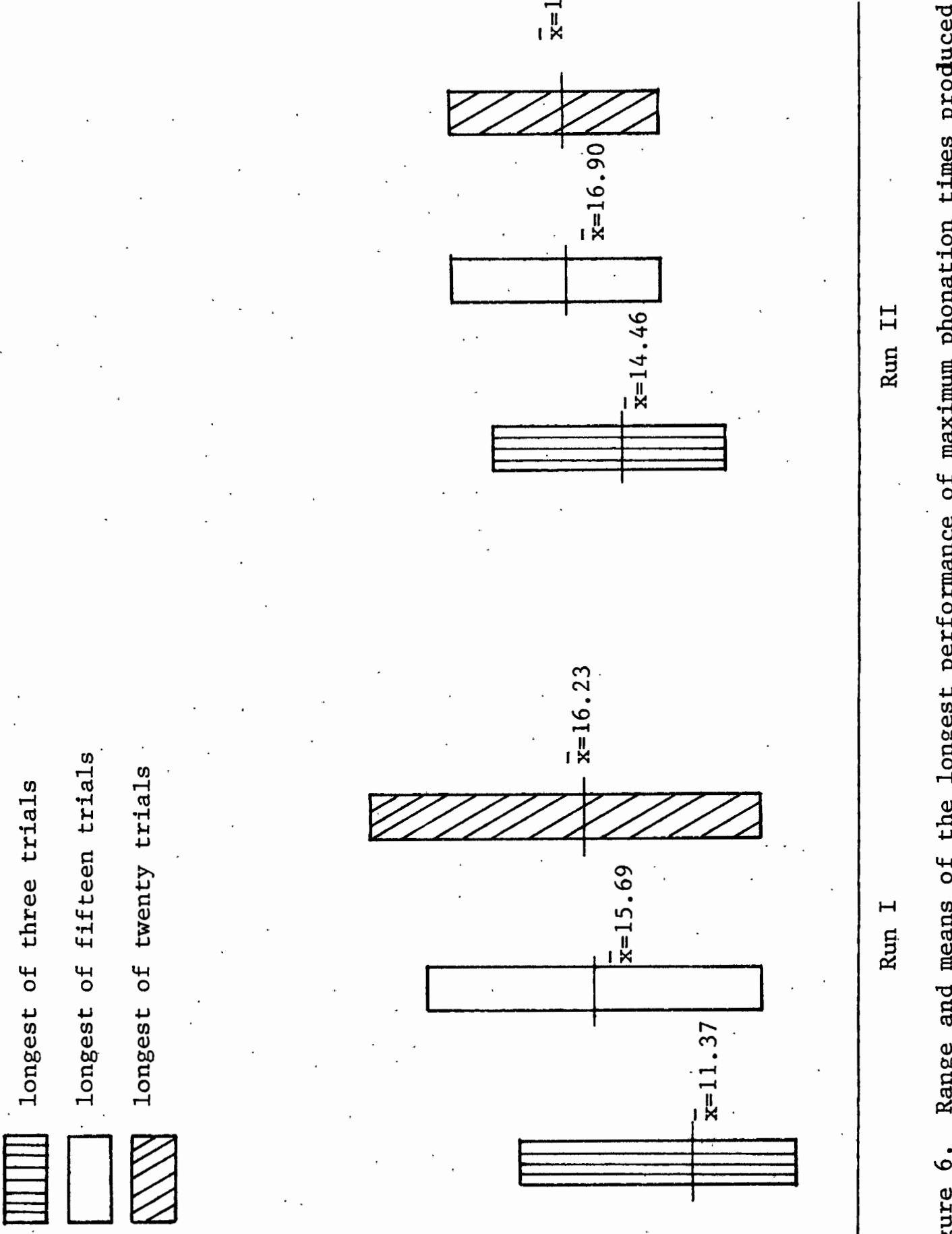

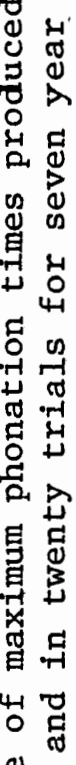

U

䨌

है

0 प्र

๑

D.

os 4

0 .

엉 का

过毕

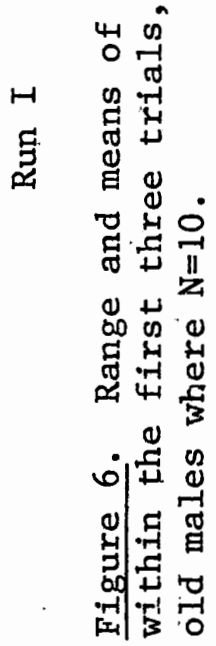

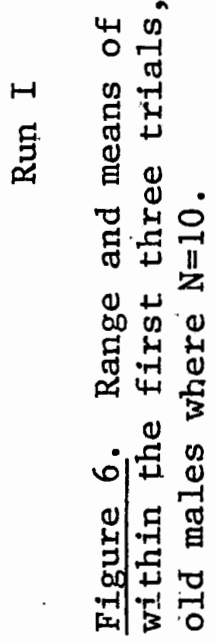

m

spuojəs uṬ /D/ fo Uoţ7euoud unuțxem fo ә8ิuey 

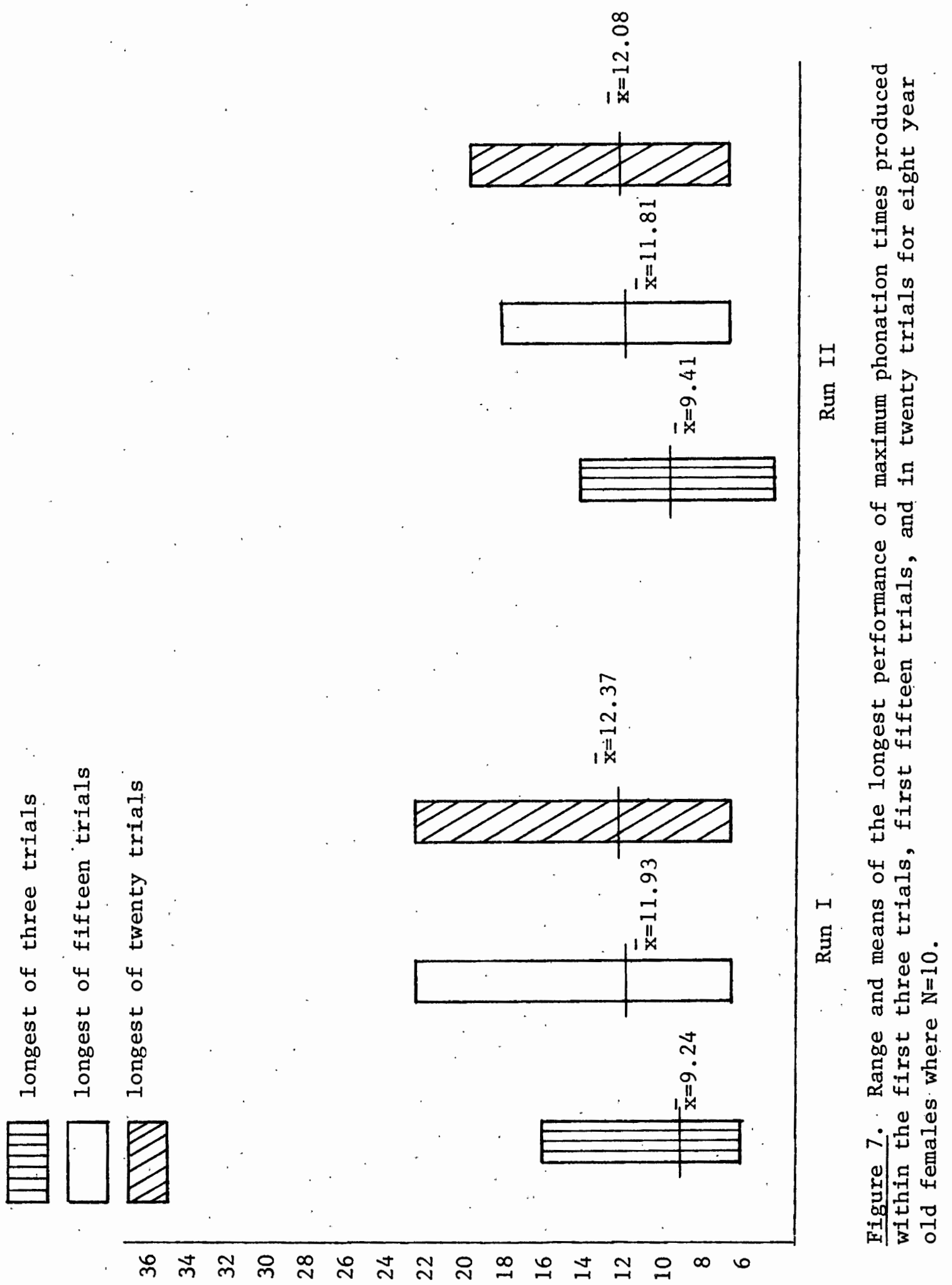

spuosəs ut $/ D /$ fo uoț7euoụd unmțxem fo ə8ిuey 


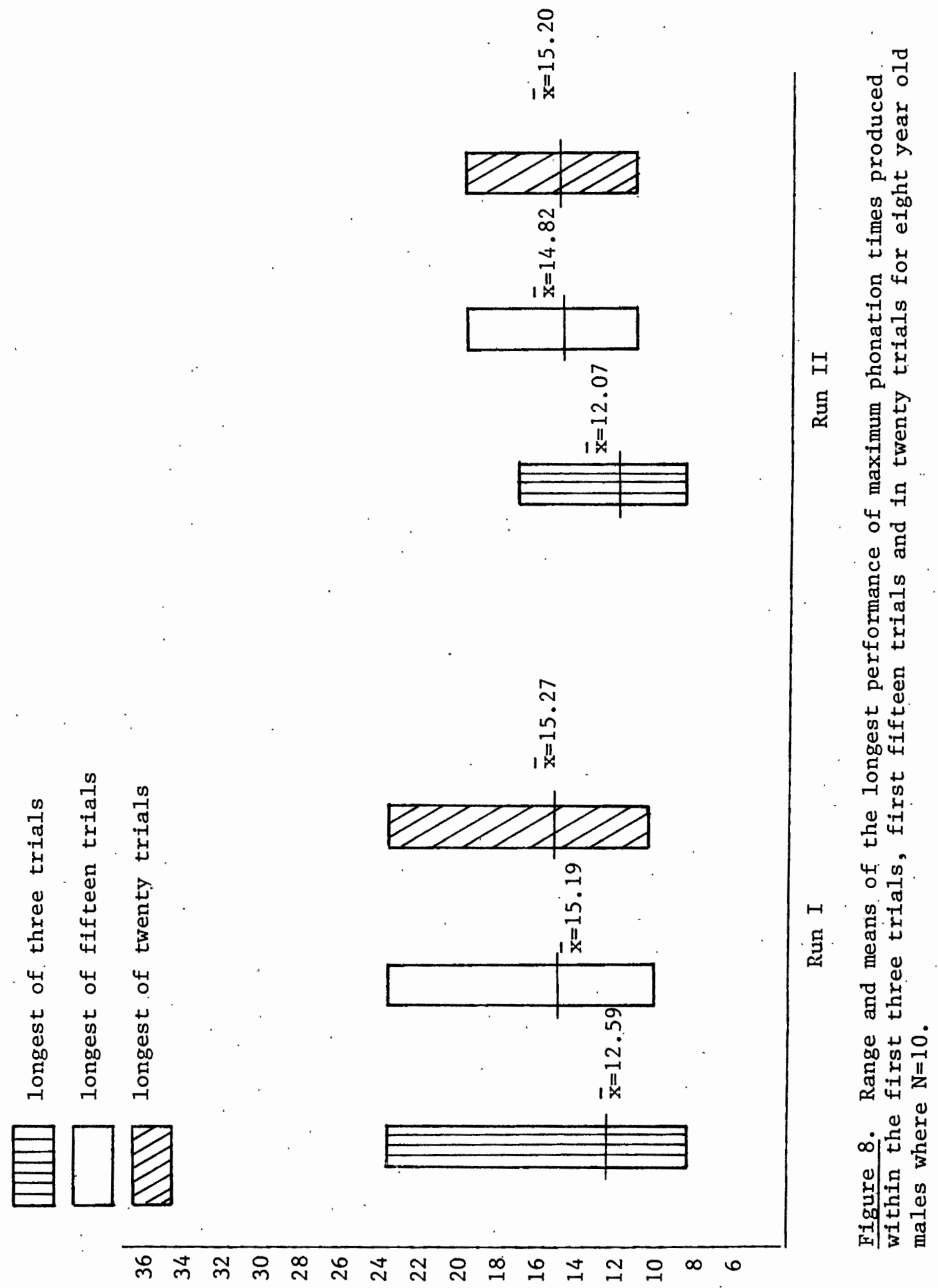

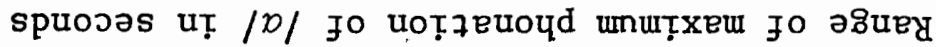



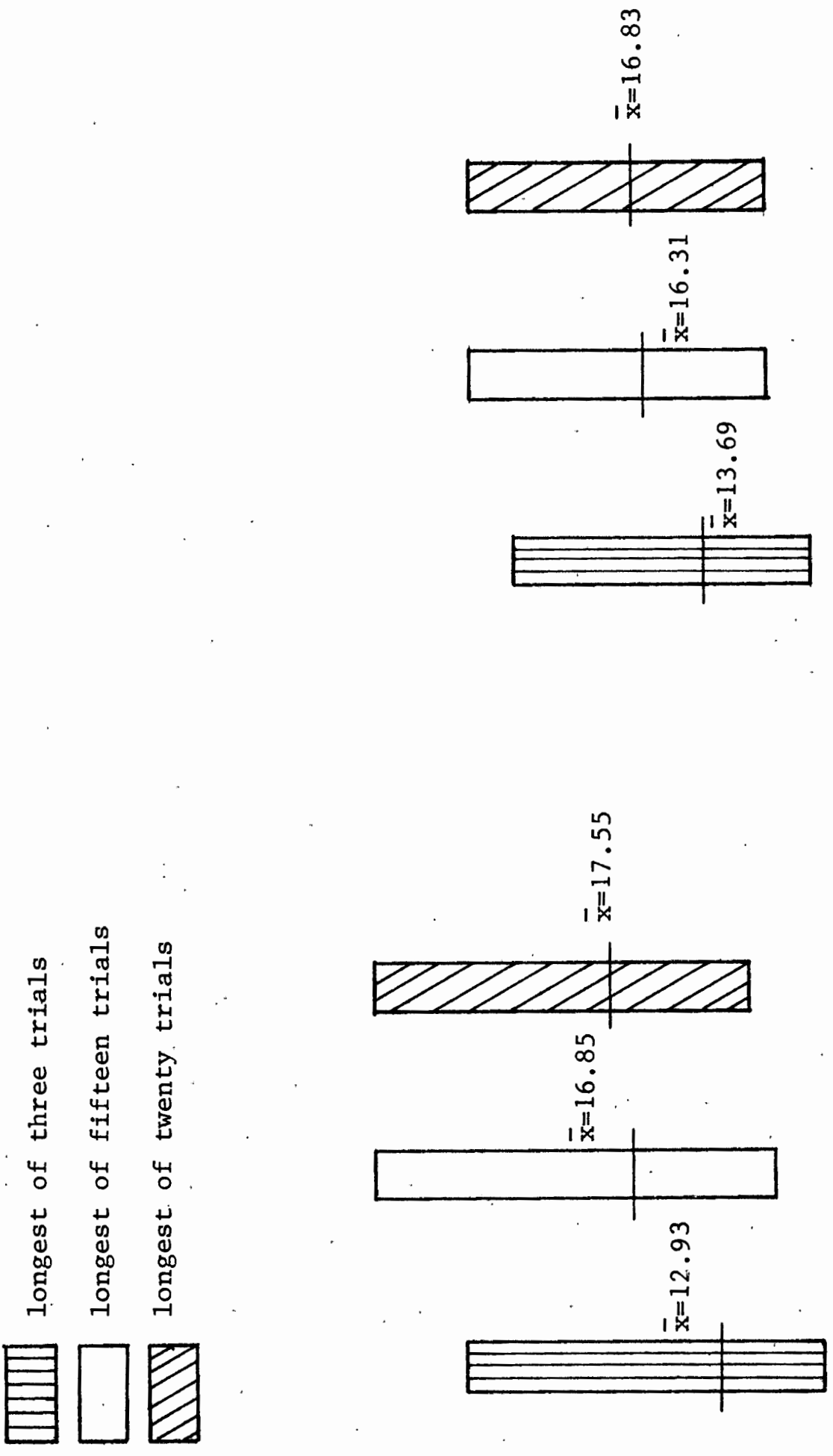

व

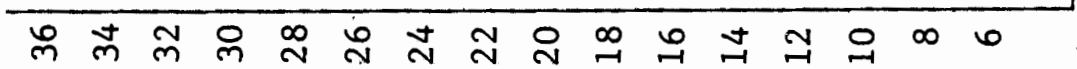

吕

貝望

4

๘

.

要

논

tr

क.

की 4

004

은

(1)

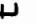

H

过出

感范

品

娄出过

\&

०

글

舟整4

spuosas uṬ $/ 0 /$ fo uoțfeuoyd mnţxew fo ə8ินey 

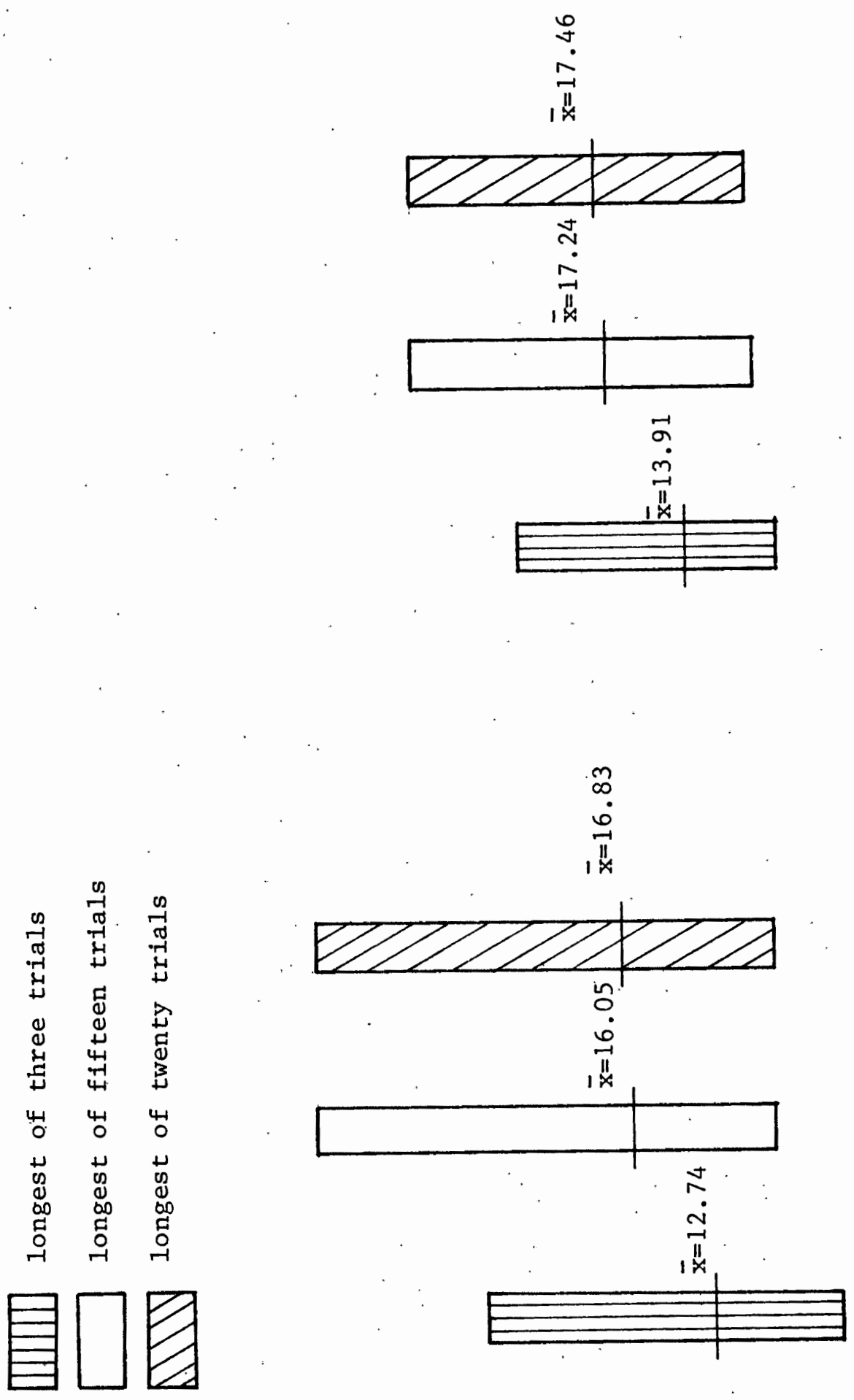

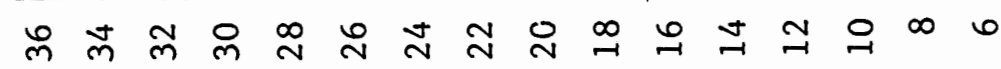
spuosəs ut $/ D /$ fo noṭfeuoud unuṭxeu fo ə8ิuey 

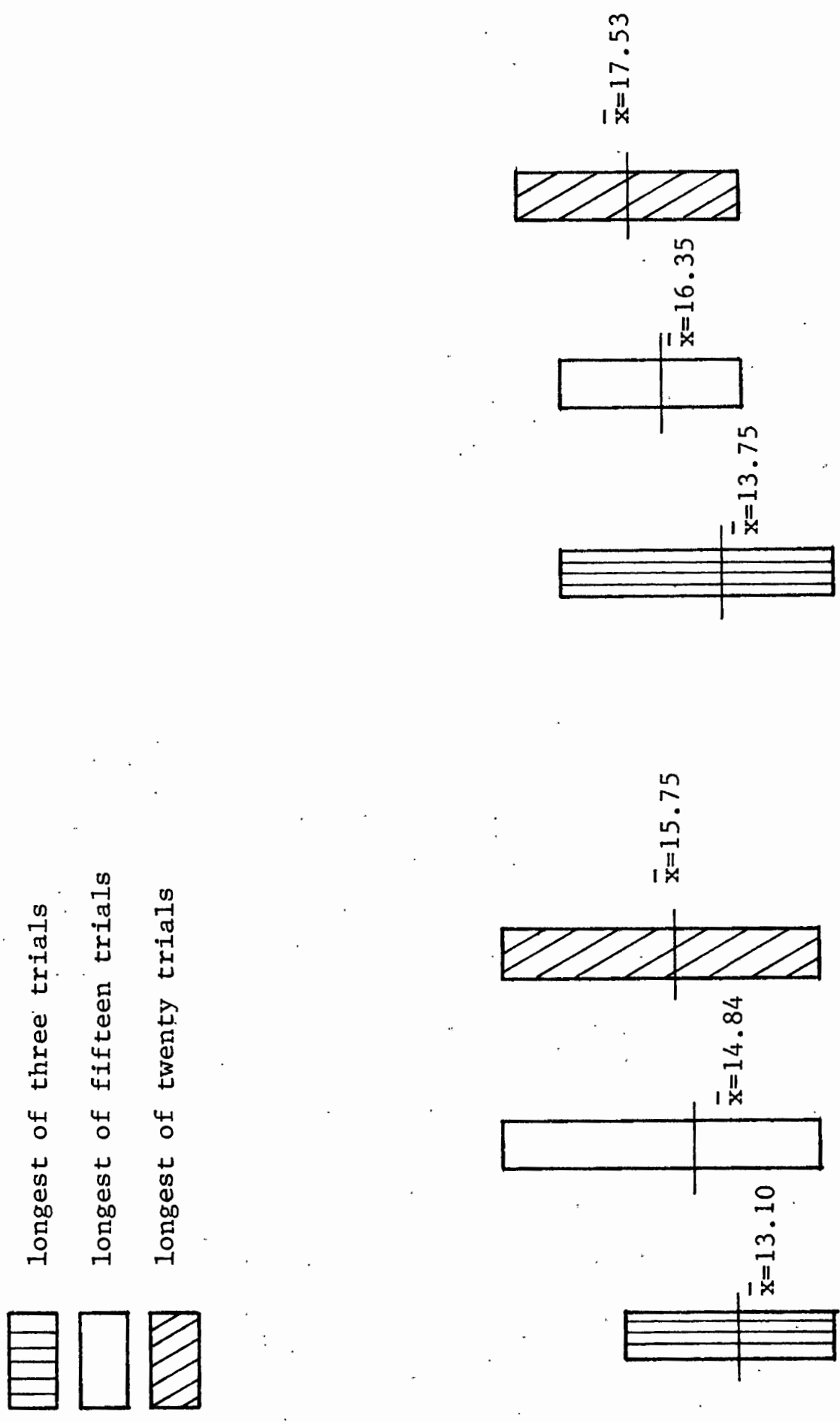

'

U ग

?

운

D. 0

路

号

म

-군

章

莺

雚

$\stackrel{H}{H}$

寻劣

썽

0 ำ

\&

苂

단

出

㟧

.

虫

勿 4

先

임

त)

包苾

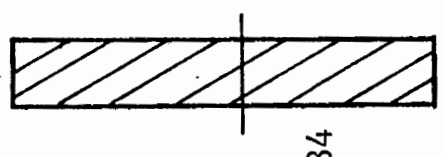

(4

4ै 0

क नु

要

要

$\mapsto$.

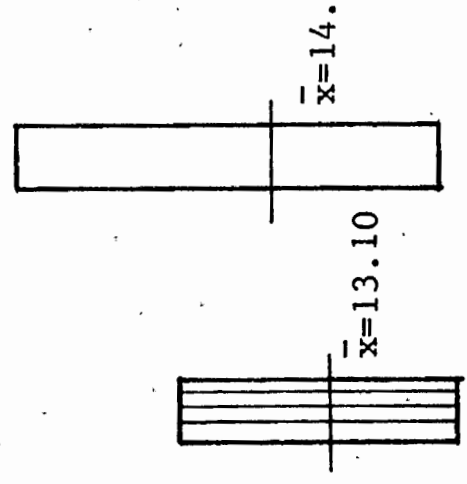

E

韋

롤

ธิ

on +11

员尔

क्ष

元委

Q) 5 O

박드

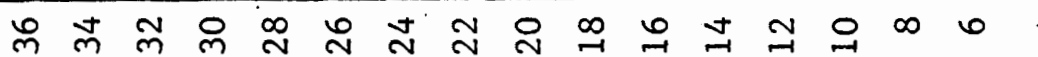

柇 3 4-

spuosas uṭ $\mid D /$ fo noṭzeuoyd unuțxew fo əsuey 

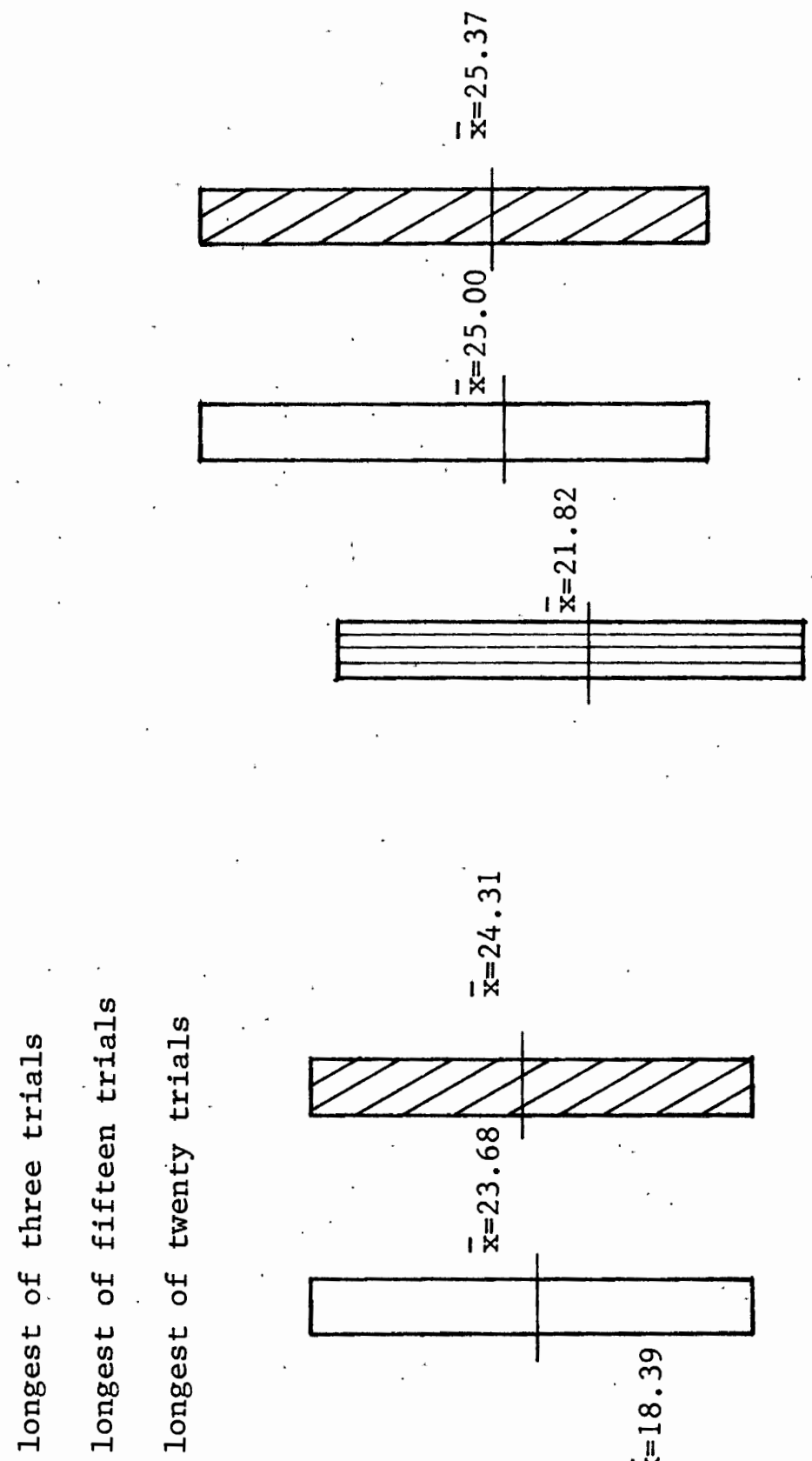

1).

,

㬂

䒠

क त्र

동

-

范

今

官 4

$\stackrel{H}{H}$

目

实

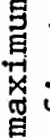

40

फु

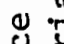

ชี

至

o

出 4

苍捳麦

$+4$

of on

of 吾

낭

ก กิ

它

म

出

08

क

- 严至

E

क्ष

正

04

일웅

สี

क ज

. 곡

인

o) 3

武导点

데웜

m

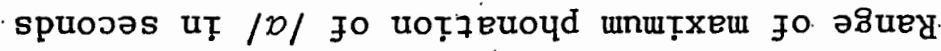


The relationship of sex to the duration of sustained /a/ was found not to be statistically significant overall (see Table IV), although a trend for males to phonate longer than females was noted. The findings: of the present investigation differ from the findings of several researchers (Ptacek and Sander, 1963; Yanagihara et al., 1966; Yanigihara and Koike, 1967; Yanagihara and von Leden, 1967; Launer, 1971; and Lewis, 1977). The results of this investigation; however, support those of the Coombs (1976) study which indicated no statistically significant correlations between sex and phonation time. The Coombs study and the present investigation, however, found a trend for males to phonate longer than females.

In the present investigation age was found to be a factor in relation to length of phonation as observed upon visual inspection of Figures 3 and 4 . These findings are consistent with the findings of Launer (1971) and Coombs (1976) but not of Lewis (1977). The Coombs (1976) study comprised a total of 192 normal and disorded voiced subjects at three age levels, six, eight, and ten. She found age to be a significant factor in the increase of maximum phonation time. The Launer (1971) study measured the phonation time of 206 boys and girls ranging in age from seven to eighteen years. Her research indicated that phonation time increases as age increases. In the present investigation the differences of the means of maximum phonation time between adjacent age groups were not large. However, between the age groups of seven and ten years of age there was an increase in the means of maximum phonation time. This is represented by the following example. In run one, seven year old males had a mean of 16.23 and in the same run, ten. year old males had a mean of 24.31 . 
In run two, seven year old females had a mean of 14.52 and ten year old females had a mean of 17.51 . 
CHAPTER V

SUMMARY AND IMPLICATIONS

\section{$\underline{\text { Summary }}$}

Maximum phonation time has been widely utilized as a simple clinical evaluation of the vocal function. Its importance has been emphasized by Van Riper (1954), Westlake and Rutherford (1961), Boone (1971), and other authors.

A review of the literature revealed three trials of sustained phonation have been utilized by most researchers to determine maximum duration of phonation. Additionally, the review revealed a lack of testretest reliability in maximum phonation time in children. An apparent need, therefore, existed to determine if twenty trials on subjects at various ages would demonstrate similar findings as the Lewis (1977) investigation as well as determine test-retest performance of the maximum duration of sustained $|a|$.

The present study was designed to determine the varfability in test-retest of maximum duration of sustained /a/ among prepubescent male and female children. Eighty subjects, twenty at each of the four age levels, seven, eight, nine and ten, were selected from a larger pool using a random order table. Each age level was further divided into two groups of ten male and ten female subjects. A tape recording of twenty maximum phonations of $|a|$ was obtained for each subject. A second measure of 
maximum phonation time was recorded between two weeks and a month following the original run. The essential questions were:

1. Given the means of age and sex groups of the longest performance of maximum duration of sustained $/ a /$, is there a significant difference between runs one and two?

2. In the test cohort does the rank order of maximum phonation time differ between runs one and two?

The following secondary questions were also posed:

1. Is there a significantly greater duration of the longest sustained $/ a /$ when given twenty trials as opposed to the first three trials?

2. Is there a relationship between sex and the duration of sustained $/ a / ?$

3. Given four prepubescent age groups, is age a factor in relation to length of phonation?

The results of the present investigation indicated the differences between runs one and two were not statistically significant and there was a high correlation between an individual's performances on runs one and two. There was a statistically significant relationship between the duration of the longest sustained $/ a /$ when given twenty trials as opposed to the first three trials. The relationship of sex to the duration of sustained /a/ was found not to be statistically significant overall, although a trend for males to phonate longer than females was noted. The relationship of age to maximum phonation time was noted by inspection to increase as age increased.

Results suggest that with the current findings on test-retest it 
would appear one could approach the use of maximum phonation time as a diagnostic tool with greater confidence when using fifteen to twenty trials.

\section{Implications}

\section{Clinical}

The results of this investigation indicated there is clinical diagnostic value in maximum phonation times in children if the number of trials is increased. It was found there was no statistical variability in performances between runs one and two. This investigation and the study by Lewis (1977) collectively show results that question previous researchers (Van Riper, 1954; Westlake and Rutherford, 1961) arbitrarily setting maximum phonation times at three trials. It was found in this investigation by visual inspection it appeared that beyond the fifteenth trial the group means, by age and sex, of maximum phonation time approached asymptote, that is the means tended to increase up to the fifteenth trial and then leveled off between trials sixteen through twenty. Certainly, from this data a run of fifteen trials would be of more value than three trials; and since there is 1ittle graphical difference between fifteen and twenty trials, it might be reasonable to assume fifteen trials could be used as a clinical standard.

\section{$\underline{\text { Reseárch }}$}

The data from this investigation suggest since there was no statistical difference between runs one and two of maximum phonation time that one run should be sufficient. Based on the results of the present 
investigation, it is suggested that further research in maximum phonation time utilize fifteen trials. This will maximize the diagnostic value of maximum phonation time in voice assessment.

The present study and the Lewis study (1977) suggest that what previous writers called normal (15-20 seconds) maximum phonation times might be too high a projection for normal prepubescent children. Further research is needed in this area to provide definitive norms for prepubescent children. 
REFERENCES CITED

ARNOLD, G., Vocal rehabilitation of paralytic dysphonia, II. Acoustic analysis of vocal function. Archives of Otolaryngology, 62, 593-601 (1955).

BECKETT, R., The respirometer as a clinical tool in the speech clinic. Journal of Speech and Hearing Disorders, 36, 235-241 (1971).

BOONE, D., The Voice and Voice Therapy. Englewood Cliffs: Prentice Ha11, Inc. $(1971)$.

COOMBS, J., The maximum duration of phonation of / $\alpha$ / in normal and hoarse voiced children. Unpublished master's thesis, Portland State University (1976).

DÖHNE, R., Dic organish bedingte einseitige Leitungsunter brcehung des Nervus laryngeus inferior und ihre Stimmveranderungen. Arch. Ohr. Nas. Kehlkopfheilk 154:96 (1944).

FAIRBANKS, G., Voice and Articularion Drillbook. (2nd ed.) New York: Harper (1960).

GUILFORD, J. P., Fundamental Statistics in Psychology and Education. (3rd ed.) New York: McGraw-Hill Co., Inc. (1965).

GUTZMANN, H., Physiologie der Stimme und Sprache. Vieweg, Brunswick (1928).

HAYASHI, Y., Lectures on the phoniatrics and 1ogopedics, part 7. Otorhinolaryngological Clinic, Kyoto 34: 210-214 (1940).

HIRANO, M., KOIKE, Y., and VON LEDEN, H., Maximum phonation time and air usage during phonation. Folia Phoniatrica, 20, 185-201 (1968).

ISSHIKI, N., OKAMURA, H., and MORIMOTO, M., Maximum phonation time and air. flow rate during phonation: Simple clinical tests for vocal function. Annals of Otology, Rhinology, and Laryngology, 76, 998-1007 (1967).

LASS, N., and MICHEL, J., The effects of frequency, intensity and voweltype on the maximum duration of phonation. Unpublished manuscript, University of Kansas (1969).

LAUNER, P., Maximum phonation time in children. Unpublished master's thesis, University of New York at Buffalo (1971).

LEWIS, K., The maximum duration of phonation of / $a /$ in children. UnpubIished master's thesis, Portland State University (1977). 
MICHEL, J. F., and WENDAHL, R., Correlates of voice production. Handbook of Speech Pathology and Audiology, L. E. Travis, ed. New York: Appleton-Century Crofts, Inc. (1971).

PTACEK, P., and SANDER, E., Maximum duration of phonation. Journal of Speech and Hearing Disorders, 28, 171-182 (1963).

SAWASHIMA, M., Measurement of Phonatory Duration. Japan Journal Logoped Phoniat. $7: 23$ (1966).

VAN RIPER, C., Speech Correction: Principles and Hethods. (3rd ed.) Englewood Cliffs: Prentice Hall (1954).

WESTLAKE, H., A system for developing speech with cerebral palsied children. National Society for Crippled Children and Adults (1952).

WESTLAKE, H., and RUTHERFORD, D., Speech Therapy for the Cerebral Palsied. Chicago: National Society for Crippled Children and Adults (1961).

WILSON, F., The voiced-disordered child: A descriptive approach. Language, Speech and Hearing Services in the Schools, 1, No. 3. 14-22 (1971).

YANAGIHARA, N., and KOIKE, Y., The regulation of sustained phonation. Folia Phoniatrica, 19, 1-18 (1967).

YANAGIHARA, . N.', KOIKE, Y., and VON LEDEN, H., Phonation and Respiration: Function study in normal subjects. Folia Phoniatrica, 18, 323-340 (1966).

YANAGIHARA, N., and VON LEDEN, H., Respiration and Phonation: The functional examination of laryngeal disease. Folia Phoniatrica, 19, 153-166 (1967). 


\section{APPENDICES}


APPENDIX A

\section{PERMISSION REQUEST}

I am a graduate student at Portland State University and have been given permission by $\mathrm{Mr}$. John Beck, school principal, to gather voice samples from 7, 8, 9 and 10 year old boys and girls for a research project at Beaumost Elementary School. I want to find out more about maximum phonation time in children; that is, the maximum amount of time an individual can say $/ a /$ after taking a breath. The results of this study will help speech clinicians to evaluate children who have voice problems.

In order to evaluate maximum phonation time, I will have your child say the vowel $/ \alpha /$ twenty times on two different occasions, two weeks apart. I will require about 15 minutes of your child's time on the two occasions. In no way will your child's name be used; I am only collecting voice samples. If you have any objections to your child being used in this study, please send back this form with your signature. If I have not received this slip within a week's time, I will assume I have your approval.

Thank you for your help.

Elena D. Norwood

Graduate Student, Speech and Hearing Portland State University

Please do not use my child in your study. Child's Name:

Parent's Signature:

Date: 
APPENDIX B

JEWISH HOSPITAL VOICE PROFILE

NAME

AGE

B.D.

GRADE

SEX

How long has the problem existed?

In what situations is the voice better or worse?

Length of sustained "ah"

$\begin{array}{llllllll}\text { Voice Rating: } & 1 & 2 & 3 & 4 & 5 & 6 & 7\end{array}$

Articulation Disorder: Yes No

LARYNGEAL CAVITY
PITCH
HIGH

B

$+3$

$+2$

A open $-4 \quad-3 \quad-2 \quad 1 \quad 2 \quad 3$ closed

$-2$

$$
-3
$$

LOW
RESONATING CAVITY

NASALITY

HYPERNASAL

$$
\begin{array}{r}
C \\
+4 \\
+3 \\
+2 \\
1 \\
-2
\end{array}
$$

HYPONASAL
CONSTANT

RATE

$-21+2$

Slow Fast
INTENSITY

$-21+2$

Soft Loud
VOCAL RANGE

$-2 \quad 1+2$

Monotone
Variable

Pitch

COMMENTS : 


\section{APPENDIX C}

\section{INSTRUCTIONS FOR ELICITING / $a /$}

"I want to find out how long people can say $/ \mathrm{a} /$, and I'd like you to help me. I want you to say /al into this microphone, like this." (Examiner models an "easy" maximum phonation of $/ a /$. )

"Now, you say /al in your lowest voice." (Examiner identifies the subject's lowest pitch on a pitch pipe, and determines a pitch three notes above the lowest pitch.)

"Good, now use that same voice and say $/ \alpha /$ for as long as you can. Ready, go."

"Good, that time you said /al for seconds. (Examiner shows the subject how many seconds were recorded on the stop watch. The examiner reinstructs and again times the subject's phonation time."

"Good, you said /al for seconds."

"This time I'm going to record you. Ready, go."

"Good, do it again." (Examiner continues until twenty maximum phonations of $\mid a /$ have been obtained from.each subject.)

Each subject was allowed to view the stop watch while phonating. 